\title{
Simulating a multi-phase tephra fall event: inversion modelling for the 1707 Hoei eruption of Mount Fuji, Japan
}

\author{
Christina Magill $^{1}$ - Kazutaka Mannen ${ }^{2} \cdot$ Laura Connor $^{3} \cdot$ Costanza Bonadonna $^{4}$. \\ Charles Connor ${ }^{3}$
}

Received: 14 February 2014 / Accepted: 11 August 2015 /Published online: 28 August 2015

(C) The Author(s) 2015. This article is published with open access at Springerlink.com

\begin{abstract}
Fuji Volcano last erupted in AD 1707 depositing approximately $40 \mathrm{~mm}$ of tephra in the area that is now central Tokyo. New high-resolution data describe 17 eruptive phases occurring over a period of 16 days (Miyaji et al., J Volcanol Geotherm Res 207(3-4):113-129, 2011). Inversion techniques were used in order to best replicate geological data and eyewitness accounts, and to estimate eruption source parameters. Inversion results based on data from individual eruptive phases suggest a total erupted mass of $2.09 \times 10^{12} \mathrm{~kg}$. Comparatively, results based on a single data set describing the entire eruption sequence suggest a total mass of $1.69 \times$ $10^{12} \mathrm{~kg}$. Values for total erupted mass determined by inversion were compared to those calculated using various curve fitting approaches. An exponential (two-segment) method, taking into account missing distal data, was found to be most compatible with inversion results, giving an erupted mass of $2.52 \times 10^{12} \mathrm{~kg}$ when combining individual phases and $1.59 \times$ $10^{12} \mathrm{~kg}$ when utilising a single data set describing the Hoei
\end{abstract}

Editorial responsibility: S. A. Fagents and J. Fierstein

Electronic supplementary material The online version of this article (doi:10.1007/s00445-015-0967-2) contains supplementary material, which is available to authorized users.

Christina Magill

christina.magill@mq.edu.au

1 Risk Frontiers, Faculty of Science and Engineering, Macquarie University, Sydney, NSW 2109, Australia

2 Hot Springs Research Institute of Kanagawa Prefecture, 586 Iriuda, Odawara, Kanagawa 250-0031, Japan

3 School of Geosciences, NES 107, University of South Florida, 4202 E. Fowler Ave., Tampa, FL 33620, USA

4 Department of Earth Sciences, University of Geneva, rue des Maraîchers 13, 1205 Geneva, Switzerland sequence. Similarly, a Weibull fitting method determined a total erupted mass of $1.54 \times 10^{12} \mathrm{~kg}$ for the single data set and compared favourably with inversion results when enough data were available. Partitioning extended eruption scenarios into multiple phases and including detailed geological data close to the eruption source, more accurately replicated the observed deposit by taking into account subtleties such as lobes deposited during transient increases in eruption rate and variations in wind velocity or direction throughout the eruption.

Keywords Hoei eruption · Inversion modelling · MountFuji · Tephra dispersal $\cdot$ Tokyo $\cdot$ Volcanic hazard

\section{Introduction}

Fundamental in understanding volcanic processes and for hazard assessment at explosive volcanoes is the characterisation of physical eruption parameters including erupted mass, plume height, eruption rate and total particle size distribution. Geophysical and remote-sensing technologies can assist in describing modern volcanic eruptions. However, past eruptions can often be studied based only on the associated stratigraphic record, which is often difficult to interpret, particularly for multi-phase eruptions where mass flow rate and particle size distribution vary with time. Inversion of analytical models is one method for the determination of physical parameters (e.g. Connor and Connor 2006; Bonasia et al. 2010; Mannen 2014; Volentik et al. 2010; Bonadonna et al. 2015a, c) but has not been tested on a long-lasting, multi-phase volcanic eruption. Here, we present a detailed investigation of the use of analytical inversions based on application to a well-known and well-studied multi-phase eruption that occurred over a 
period of 16 days: the AD 1707 Hoei eruption of Mount Fuji (Miyaji et al. 2011).

Tephra from this most recent eruption of Fuji Volcano covered most of the South Kanto plain (Fig. 1) and has been found in the Northwest Pacific Ocean, $270 \mathrm{~km}$ from source (Machida and Arai 1988). Approximately $100 \mathrm{~km}$ eastnortheast of the volcano in Edo, now central Tokyo, tephra fall was estimated to have been approximately $40 \mathrm{~mm}$ in thickness (Miyaji et al. 2011). The 1707 eruption was the most violent, and one of the largest in volume, from Younger Fuji Volcano, which has formed over the past 11 ky (Miyaji 2002, 2011; Takada et al. 2011).

A review of historical documents by Inoue (2011) showed that during the Hoei eruption, houses in the Mikuriya area at the eastern foot of the volcano were destroyed by tephra up to $3 \mathrm{~m}$ thick. In Subashiri, the village nearest to the craters, 72 houses and three Buddhist temples were either buried by thick hot tephra deposits or destroyed by fire caused by hot volcanic bombs (Ishii et al. 2007). Lahars and floods caused by clogging of irrigation channels by tephra-affected areas as far away as what is now Yokohama; notably, large floods occurred in the Sakawa River in 1711, 1731 and 1802, nearly 100 years after the eruption (Inoue 2011; Sumiya et al. 2002).
Failure of crops and resulting famine were also reported by Inoue (2011).

The population within the ash-affected area is assumed to have been over 3 million (Hayami 1993). In the area severely damaged by thick ash falls and lahars, and within the Odawara Domain of the time, agricultural production valued at 56,384 koku (equivalent to $10,171 \mathrm{~m}^{3}$ of rice) was temporarily trusted to the Shogunate government (City of Odawara 1999). The population of this area is not known but, from the measure of productivity, can be estimated to be approximately 50,000 . Now, over 30 million people now live in the area estimated by Miyaji et al. (2011) to have been impacted by more than $10 \mathrm{~mm}$ of tephra. This includes almost the entire land area of Kanagawa and Chiba prefectures, the highly populated eastern area of Tokyo prefecture and parts of Shizuoka, Yamanashi and Saitama prefectures (Fig. 1).

The area affected is now home to Japan's national government and is a major national and international hub for business, manufacturing and transport. If a similar eruption were to occur today, we could expect significant disruptions to these sectors as well as damage to buildings and infrastructure, and impacts to agriculture and human health. The clean-up requirements for such an event would be immense with
Fig. 1 Tephra thickness isopachs $(\mathrm{mm})$ for the 1707 Hoei eruption of Fuji volcano (modified from Miyaji et al. (2011)). Locations: $E$, Edo or central Tokyo; $H$, Hongo Campus, University of Tokyo; $Y$, Yokohama; $O$,

Odawara; $S$, Subashiri; $N$, Narita Airport. Fuji volcano is marked by a white triangle. White lines indicate the boundaries of affected prefectures: Tokyo $(T o)$, Kanagawa $(\mathrm{Ka})$, Chiba $(\mathrm{Ch})$, Saitama ( $S a)$, Ibaraki (Ib), Yamanashi $(Y a)$ and Shizuoka (Sh). The South Kanto Plain typically refers to Tokyo, Kanagawa, Chiba and Saitama prefectures. Tributaries in the north of Shizuoka, east of Fuji Volcano, contribute to the Sakawa River, which enters the sea at Odawara. Inner isopachs are not annotated but represent 1280 and $2560 \mathrm{~mm}$ extents

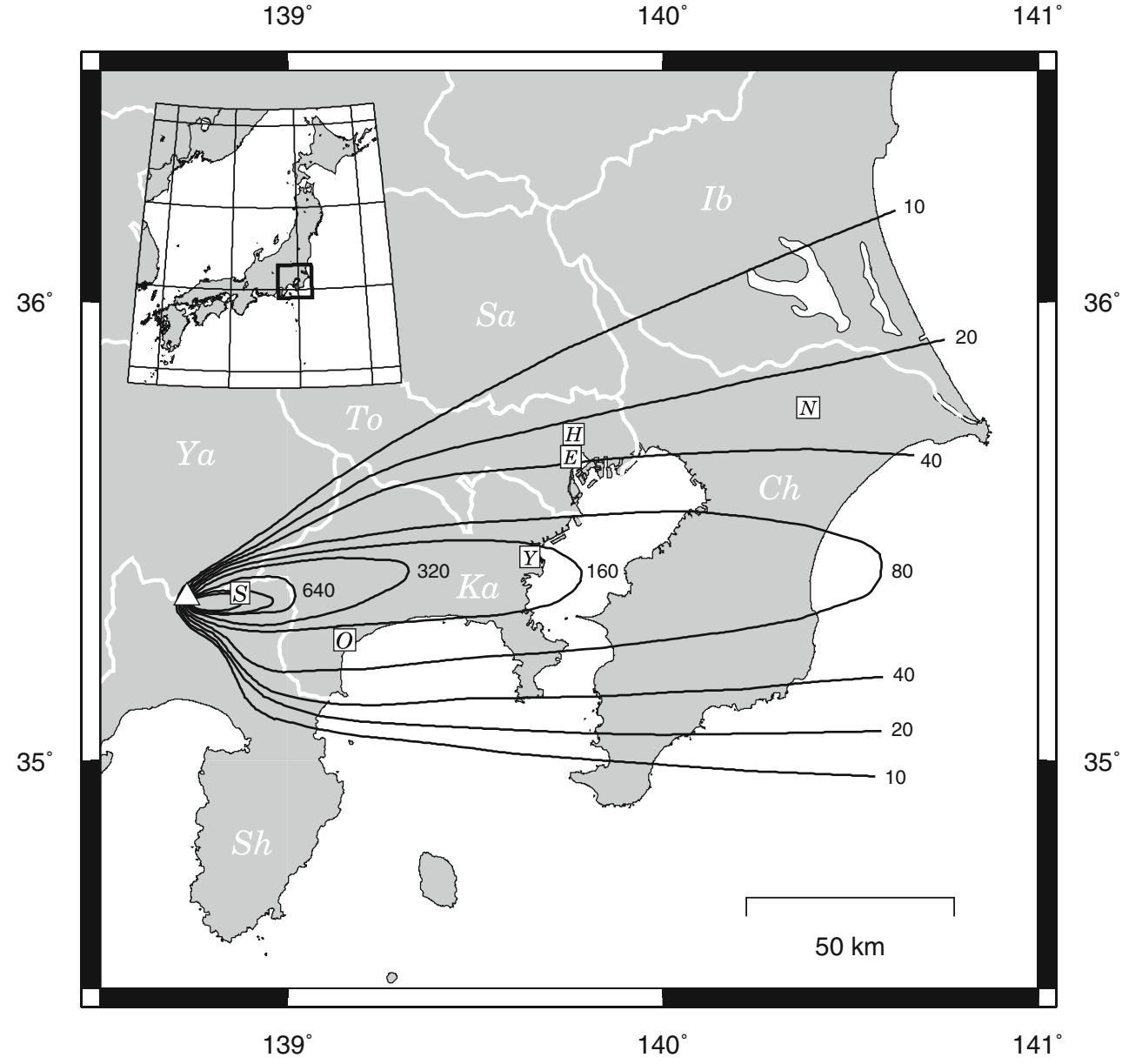


considerable assistance and resources having to be sourced from outside the affected area.

A detailed assessment of the hazard posed by tephra fall from Fuji Volcano was carried out by Cabinet Office (2004) based on the 1707 eruption. This study utilised a Regional Meso-Scale Model of Japan Meteorological Agency (JMA), and a nested advection-diffusion model developed by the Meteorological Institute, to replicate the four main stages of the Hoei eruption using averaged observed meteorological information for December (1957-2001) and reconstructed tephra thickness distribution for the Hoei eruption (Miyaji 1984; Shimozuru 1983; Miyaji and Koyama 2002). The study simulated three scales of potential eruption occurring at each month of the year. Calculated contours were shifted horizontally to include uncertainty in vent location.

Here, we employed new high-resolution data describing 17 phases of the Hoei eruption (Miyaji et al. 2011) and inversion techniques to replicate discrete periods of the eruption. In addition, we undertook a single set of inversion runs using data describing the eruption sequence as a whole. We analysed the success of inversion methods in replicating the Hoei deposit and compared calculated erupted mass with results from alternative curve-fitting approaches.

\section{Inversion using Tephra2}

In this study, we utilised the analytical tephra advection-diffusion model Tephra2 (Bonadonna et al. 2005; Connor and Connor 2006). Tephra2 is based on the model developed by Suzuki (1983) and subsequently modified by a number of authors: see Bonadonna et al. (2005) for a full description. Tephra 2 calculates particle diffusion, transport and sedimentation from an explosive eruption to estimate tephra accumulation at specified locations surrounding the source volcano. Particles are assumed to be spherical and their settling velocity is determined as a function of particle size and density, atmospheric properties and Reynolds number (Bonadonna et al. 1998). Vertical atmospheric diffusion and vertical wind speed are assumed negligible and a constant and isotropic horizontal diffusion coefficient is implemented (Bonadonna et al. 2005). A fall time threshold is considered to select between two possible diffusion models, one for coarse particles (a linear model) and one for fine particles (a non-linear model). Particles fall through and are transported by a wind speed and direction profile that varies vertically and is constant in the horizontal direction, and are accumulated at ground level to determine total tephra load $\left(\mathrm{kg} \mathrm{m}^{-2}\right)$.

To replicate the phases of the Hoei eruption, we utilised inversion techniques developed by Connor and Connor (2006). A downhill simplex method was employed to determine an optimal set of eruption parameters for Tephra2 that, when applied, best replicated field measurements given by
Miyaji et al. (2011). The downhill simplex method is a geometric approach where $N$ independent parameters are defined as $N+1$ vertices in $N$-dimensional space. The vertices are then systematically shifted towards the centroid of the simplex to find the minimum of a function describing the $N$ independent parameters. The calculation ends when the location of the vertices lie within a given tolerance distance from the centroid (Nelder and Mead 1965; Press et al. 2007).

Using this non-linear inversion process, the total erupted mass, eruption plume height, distribution of mass within the eruption plume, particle size distribution and wind velocity within each atmospheric layer were varied to determine the eruption dynamics needed to best replicate tephra accumulation measured or observed at specific locations. With each iteration, source parameters were modified and tephra accumulation for given particle size categories were calculated for each location using the forward solution model Tephra2. A root mean square error (RMSE) was calculated to describe the goodness-of-fit between the measured and simulated deposit:

$\mathrm{RMSE}=\sqrt{\frac{\sum_{i=1}^{n}\left(M s_{i}-M o_{i}\right)^{2}}{n}}$

where $n$ is the number of observations, $M o_{i}$ the observed or measured accumulation at location $i$ and $M s_{i}$ the simulated accumulation at location $i$. Multiple inversions were run with different initial seeds or starting values (i.e. the seed value initialised the generation of random values) to account for the possibility of parameters being adjusted towards a local minimum (Connor and Connor 2006).

\section{Hoei eruption inversion}

Because of the close proximity of Mount Fuji to Edo, documents and drawings of the time (see Inoue 2011; Koyama 2011; Sumiya et al. 2002) have allowed, when combined with detailed geological investigations (for example, Miyaji 1984; Miyaji et al. 2011; Miyaji and Koyama 2011; Tsuya 1955; Watanabe et al. 2006), an accurate detailed chronology of the Hoei event. Eruptive activity began at approximately 10 $\mathrm{AM}$ on the 16th of December with a Plinian eruption plume on the south-eastern flank dispersing widespread pumice towards the east. After approximately $6 \mathrm{~h}$, the tephra became darker in colour and on the morning of the 17 th the eruption became less violent. Eruptions were intermittent until the evening of December 25th and then increased again until the 27th. After this date, activity decreased and ceased completely on the morning of January 1st, 1708 (Koyama 2011; Miyaji 1984, 2002).

Units within the 1707 tephra deposits were divided into four groups, Ho-I to Ho-IV, as defined by Miyaji (1984). Ho-I is dacite to andesite and was deposited on 
the first day of the event. Ho-II is andesitic and Ho-III and IV basaltic (Miyaji 2002; Watanabe et al. 2006). The average mass eruption rate throughout the eruption sequence was estimated at $5 \times 10^{9} \mathrm{~kg}$ per hour and, during the deposition of Ho-I and Ho-II, $2.7 \times 10^{10} \mathrm{~kg}$ per hour (Miyaji et al. 2011).

Miyaji et al. (2011) revised previous geological and historical studies and subdivided the eruption deposit into 17 units designated from $\mathrm{A}$ to $\mathrm{Q}$, with $\mathrm{A}$ representing the earliest phase of the eruption. Thickness information at point locations for each phase of the eruption and for the eruption sequence as a whole were provided; isomass maps were constructed; and mass, flux and eruption plume height estimations were made. The number of deposit point locations, duration of each phase, as well as estimated erupted mass and maximum plume height are summarised in Table 1, with readers directed to Miyaji et al. (2011), Miyaji (1984) and Watanabe et al. (2006) for more detail. Inversion modelling described below aims to replicate deposit characteristics provided at the phase level by Miyaji et al. (2011). As a further investigation, these multiphase results were compared with results obtained from inversion of a single set of data that describes the entire eruption sequence.

Table 1 Eruption parameters [erupted mass, duration, plume height and neutral buoyancy $(\mathrm{Nb})$ height] estimated from geological investigations and historical documents for each phase of the Hoei

\begin{tabular}{|c|c|c|c|c|c|c|c|c|c|c|}
\hline Group & Phase & $\begin{array}{l}\text { Number } \\
\text { of points* }\end{array}$ & $\begin{array}{l}\text { Mass } \\
\left(\times 10^{10} \mathrm{~kg}\right)^{*}\end{array}$ & $\begin{array}{l}\text { Duration } \\
(\mathrm{h})^{*}\end{array}$ & $\begin{array}{l}\text { Height } \\
(\mathrm{km})^{*}\end{array}$ & $\begin{array}{l}\mathrm{Nb} \\
\text { height } \\
(\mathrm{km})^{*}\end{array}$ & $\begin{array}{l}\text { Minimum } \\
\text { simulated mass } \\
\left(\times 10^{10} \mathrm{~kg}\right)\end{array}$ & $\begin{array}{l}\text { Maximum } \\
\text { simulated mass } \\
\left(\times 10^{10} \mathrm{~kg}\right)\end{array}$ & $\begin{array}{l}\text { Minimum } \\
\text { simulated } \\
\text { height }(\mathrm{km})\end{array}$ & $\begin{array}{l}\text { Maximum } \\
\text { simulated } \\
\text { height }(\mathrm{km})\end{array}$ \\
\hline \multirow[t]{2}{*}{ I } & A & 69 & $5.7 \pm 0.3$ & 1.5 & $23_{-3}^{+5}$ & $17_{-2}^{+3}$ & 1.14 & 28.5 & 15 & 28 \\
\hline & B & 35 & $44_{-0.4}^{+0.3}$ & 4.0 & $18_{-3}^{+4}$ & $14_{-3}^{+4}$ & 0.88 & 22 & 11 & 22 \\
\hline \multirow[t]{4}{*}{ II } & $\mathrm{C}$ & 28 & $26_{-1}^{+0}$ & 8.0 & $22_{-3}^{+4}$ & $17_{-2}^{+3}$ & 5.2 & 130 & 15 & 26 \\
\hline & $\mathrm{D}$ & 18 & $8.9_{-0.8}^{+0.4}$ & 5.0 & $19_{-3}^{+5}$ & $15_{-3}^{+4}$ & 1.78 & 44.5 & 12 & 24 \\
\hline & $\mathrm{E}$ & 19 & $13 \pm 1$ & 15.5 & $18_{-3}^{+4}$ & $14_{-3}^{+4}$ & 2.6 & 65 & 11 & 22 \\
\hline & F & 23 & $5.5_{-0.5}^{+0.1}$ & & & & 1.1 & 27.5 & 11 & 22 \\
\hline \multirow[t]{7}{*}{ III } & G & 17 & $2.1_{-0.2}^{+0.1}$ & 15.5 & $12_{-3}^{+4}$ & $10_{-2}^{+3}$ & 0.42 & 10.5 & 8 & 16 \\
\hline & $\mathrm{H}$ & 16 & $14 \pm 1$ & 17.5 & $17_{-3}^{+4}$ & $13_{-3}^{+4}$ & 2.8 & 70 & 10 & 21 \\
\hline & I & 14 & $6.6_{-1.2}^{+0.8}$ & 16.0 & $15_{-3}^{+4}$ & $12_{-3}^{+4}$ & 1.32 & 33 & 9 & 19 \\
\hline & $\mathrm{J}$ & 14 & $12_{-1}^{+0}$ & 16.5 & $16_{-3}^{+4}$ & $13_{-3}^{+4}$ & 2.4 & 60 & 10 & 20 \\
\hline & K & 18 & $6.2_{-0.6}^{+0.5}$ & 8.5 & $16_{-3}^{+4}$ & $13_{-3}^{+4}$ & 1.24 & 31 & 10 & 20 \\
\hline & $\mathrm{L}$ & 24 & $18 \pm 2$ & 9.0 & $20_{-3}^{+5}$ & $15_{-3}^{+4}$ & 3.6 & 90 & 12 & 25 \\
\hline & M & 22 & $4.1_{-0.5}^{+0.4}$ & 8.0 & $15_{-3}^{+4}$ & $12_{-3}^{+4}$ & 0.82 & 20.5 & 9 & 19 \\
\hline \multirow[t]{4}{*}{ IV } & $\mathrm{N}$ & 17 & $10_{-2}^{+1}$ & 4.5 & $20_{-4}^{+5}$ & $16_{-3}^{+4}$ & 2 & 50 & 13 & 25 \\
\hline & $\mathrm{O}$ & 9 & $13_{-2}^{+1}$ & 33.5 & $15_{-3}^{+4}$ & $11_{-3}^{+5}$ & 2.6 & 65 & 8 & 19 \\
\hline & $\mathrm{P}$ & 6 & $11_{-2}^{+1}$ & 11.5 & $17_{-3}^{+5}$ & $13_{-3}^{+4}$ & 2.2 & 55 & 10 & 22 \\
\hline & Q & 4 & $18_{-4}^{+3}$ & 57.0 & $14_{-3}^{+4}$ & $11_{-3}^{+4}$ & 3.6 & 90 & 8 & 18 \\
\hline \multicolumn{2}{|c|}{ Hoei sequence (HS) } & 101 & $179_{-7}^{+13}$ & & & & 36 & 900 & 8 & 28 \\
\hline
\end{tabular}

*Values from Miyaji et al. (2011). For mass, subscript and superscript values represent errors determined by least squares fitting. In the calculation of Height and $\mathrm{Nb}$ height, subscript and superscript values represent uncertainties in mass estimation, atmospheric structure and eruption duration (assumed to be as high as $50 \%$ )

\section{Inversion parameters}

Inversion was based primarily on thickness information given by Miyaji et al. (2011) after applying their assumed deposit density of $1000 \mathrm{~kg} \mathrm{~m}^{-3}$. Inversion runs were carried out separately for each eruption phase (A-Q) and for the Hoei eruption sequence as a whole (hereafter referred to as HS). Our modelling only utilised thickness information for specific point locations and did not consider previously constructed isomass maps, such as that from Miyaji et al. (2011) shown in Fig. 1.

Due to the high consequences associated with tephra fall affecting the metropolitan area of Tokyo, particular scrutiny was given to estimates of tephra accumulation within this area. However, due to urban development, only a single location has been found to provide adequate geological information. At Hongo Campus, the University of Tokyo (Fig. 1), the total Hoei deposit was reported to be approximately $20 \mathrm{~mm}$ in thickness, with phase A identifiable as a layer approximately $2 \mathrm{~mm}$ in thickness (Miyaji and Koyama 2011; T. Fujii, personal communication, September 2014). For the inversion of phase A and HS, we include these estimates at this location (hereafter referred to as Hongo).

eruption and for the total eruption sequence (marked by *), with corresponding erupted mass and plume height ranges simulated by inversion 
Inversion commences with a random value chosen from a defined range for each model parameter. Each consecutive iteration compares model-calculated values with field measurements (Eq. 1) and adjusts the model input parameters to progress to a best-fit solution (Connor and Connor 2006). The parameters investigated were total erupted mass, maximum plume height, distribution of mass within the plume, median particle size (phi), standard deviation particle size (phi), diffusion coefficient, fall time threshold, and wind speed and direction at equal intervals above the erupting vent.

Inversion sensitivity, including the possible occurrence of local minima, was assessed by performing multiple inversions with comparatively narrow ranges for selected critical parameters. For each phase, erupted mass and maximum plume height were divided into ten narrower ranges. The minimum erupted masses considered (Table 1) were approximately five times smaller than that estimated by Miyaji et al. (2011) and the maximum approximately five times larger. To best replicate the maximum release height of particles, plume heights were sampled between the minimum neutral buoyancy height (the level where the plume spreads after reaching the same density as the surrounding atmosphere) and the maximum plume height estimated by Miyaji et al. (2011) (Table 1).

For all inversion simulations, we assumed a minimum particle size of 6.0 phi and a maximum of -6.0 phi to adequately cover the range measured by Miyaji (1984). The median particle size was allowed to vary between 3.0 and -3.0 phi (after Miyaji 1984) and the standard deviation between 0.5 and 3.0 phi. The wind speed at each height interval was sampled between 10 and $120 \mathrm{~m} \mathrm{~s}^{-1}$, acceptable in this location, and the wind direction between 225 and $315^{\circ}$ ( 225 and $340^{\circ}$ for phase D), as witnessed during the 1707 eruption. For simplicity, vent elevation was fixed at $2500 \mathrm{~m}$; lithic density was assumed to be $2600 \mathrm{~kg} \mathrm{~m}^{-3}$ and pumice density $1000 \mathrm{~kg} \mathrm{~m}^{-3}$ (approximate means through Hoei sequence as measured by Miyaji 1984).

In advection-diffusion models, the width of the simulated deposit and the maximum thickness along the dispersal axis are mostly controlled by particle diffusion, which, in Tephra2, is described by a linear and a power-law function for coarse and fine particles, respectively (Bonadonna et al. 2005; Courtland et al. 2012). For coarse particles, we indicate those that have fall times less than the fall time thresholds typically determined empirically through model inversions of field observations (e.g. Bonadonna et al. 2005). The diffusion coefficient describes the diffusion of coarse particles through the atmosphere and values may range from an order of 1 to 10 , $000 \mathrm{~m}^{2} \mathrm{~s}^{-1}$ (Heffter 1965; Pasquill 1974; Suzuki 1983; Bonadonna et al. 2005). Values of fall time threshold can realistically range from an order of 1 to $10,000 \mathrm{~s}$. To constrain each simulation, the diffusion coefficient here was allowed to vary between 1 and $1000 \mathrm{~m}^{2} \mathrm{~s}^{-1}$ and the fall time threshold between 1 and $250 \mathrm{~s}$. It is important to note that the diffusion coefficient in semi-analytical advection-diffusion models, such as Tephra2, does not describe only atmospheric diffusion, but also gravitational spreading and other sedimentation processes that are not specifically defined in the model. As a result, the diffusion coefficient is larger than measured atmospheric diffusivity (e.g. Volentik et al. 2010; Bonadonna et al. 2015b).

\section{Mass distribution within plume}

Ash dispersion is in part controlled by the release height of particles with, when all other parameters are consistent, those released from lower elevations accumulating closer to the vent. The relative release height of particles may be approximated by the distribution of mass within the simulated eruption plume. Previous modelling carried out with Tephra2 assumed a linear distribution of mass between the maximum plume height and a given lower limit (Bonadonna et al. 2002, 2005; Biass and Bonadonna 2012). Bonadonna et al. (2002) tested various mass distributions by simulating Vulcanian plumes with (1) mass concentrated half-way between the neutral buoyancy height and the plume height, (2) mass distributed linearly between the neutral buoyancy height and the maximum plume height, and (3) mass distributed according to Suzuki (1983), where the highest concentration of particles are typically located around the height of neutral buoyancy. For these short-lived plumes, it was found that the uniform distribution gave the best results. Further studies considered a lognormal distribution of mass within the plume with mass concentrated primarily in the upper section (Bonadonna et al. 2005).

Here, we investigate the effectiveness of distributing mass in a vertical plume based on a beta probability density function:

$P(x)=\frac{(1-x)^{\beta-1} x^{\alpha-1}}{B(\alpha, \beta)}$

where $B(\alpha, \beta)$ is the beta function and $\alpha, \beta>0$. A uniform distribution is described when $\alpha$ and $\beta$ are both equal to 1 ; when $\alpha>\beta$, the distribution is skewed and a greater amount of ash is released towards the top of the plume.

Rather than allowing $\alpha$ and $\beta$ to be determined by inversion, eight beta probability density functions (PDFs) were simulated (Fig. 2). PDF 1 is the uniform distribution with $\alpha$ and $\beta$ both equal to 1 . The values of $\alpha$ and $\beta$ were adjusted in PDFs 2 to 8 so that with each consecutive distribution, a greater amount of ash was distributed towards the top of the plume, i.e. potentially representing a more intense umbrella region. PDFs 2, 3 and 4 represented plumes where mass was preferentially concentrated in the lower part of the plume. These distributions may more accurately represent situations 


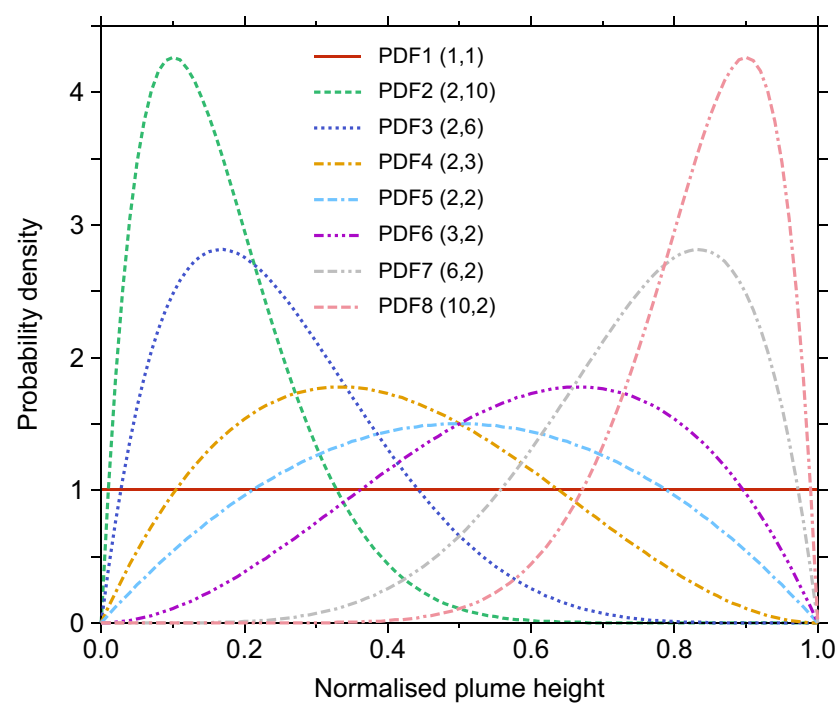

Fig. 2 Probability density functions (PDFs) describing the mass distribution and release of tephra from the eruption plume. On the horizontal axis, 0 represents vent height and 1 the maximum height of the eruption plume. Values for $(\alpha, \beta)$ define the shape of each PDF and are shown in the legend

such as that described by Fero et al. (2009) where the largest concentration of ash is released from a height much lower than the maximum plume height.

Each set of inversion runs (phases A-Q and HS) consisted of ten ranges of mass, ten ranges of plume height and eight PDFs of mass within the plume. For each of these possibilities, we applied ten different random number seeds to give a total of 8000 inversion runs per phase and for HS. To increase efficiency, computations were performed in parallel using a message passing interface (MPI). Measured tephra accumulation points were divided equally among multiple processors with tephra accumulation calculated independently for each location. Results were compiled and RMSE calculated on a master node.

\section{Phase A inversion}

To demonstrate the inversion methodology, we describe in detail the steps undertaken to replicate phase A of the Hoei eruption. Unit A represents the initial Plinian phase and is distinct because of its pale colour (Miyaji 1984; Miyaji et al. 2011). Lasting approximately $1.5 \mathrm{~h}$, this was the most energetic phase of the eruption, exhibiting the highest plume (Miyaji et al. 2011). Measurements of ash accumulation for phase A were described for 69 locations ranging from $600 \mathrm{~kg} \mathrm{~m}^{-2}, 3 \mathrm{~km}$ to the east of the Hoei craters (Miyaji et al. 2011), to $2 \mathrm{~kg} \mathrm{~m}^{-2}, 100 \mathrm{~km}$ northeast (Miyaji and Koyama 2011).

Using the method proposed by Pyle (1989), who considered the exponential decay of deposit thickness as a function of the square root of the area enclosed by the corresponding isopach, Miyaji et al. (2011) calculated a mass of $5.7 \pm 0.3 \times$ $10^{10} \mathrm{~kg}$ for phase A of the Hoei eruption. Koyama and Maejima (2009) estimated from eyewitness accounts that the plume was at least $20 \mathrm{~km}$ high and Miyaji et al. (2011) concluded a height between 20 and $28 \mathrm{~km}$ with the neutral buoyancy height between 15 and $20 \mathrm{~km}$. Inversion simulations for this phase sampled mass between $1.14 \times 10^{10}$ and $2.85 \times$ $10^{11} \mathrm{~kg}$, divided using a log scale into ten narrower ranges. Plume height was sampled between 15 and $28 \mathrm{~km}$, divided into ten equal ranges of $1.3 \mathrm{~km}$.

Considering each set of inversions, represented by a unique erupted mass range, plume height range and mass PDF, and using a unique random number seed, the simulation producing the lowest RMSE (Eq. 1), or best fit to the measured data, was kept for further analysis, i.e. 800 best-fit inversions representing different erupted mass, plume height and mass PDF combinations. The results for phase A are presented in Fig. 3, with key parameters plotted against RMSE. Points of different colour represent the eight mass PDFs applied. Although simulations resulted in a wide range of RMSE values depending on the allowed ranges of total mass and plume height, and the distinct mass PDF, in general the lowest values were calculated when using PDF 4 (Fig. 3a). This suggests that for phase A, PDF 4 with a higher concentration of tephra in the lower portion of the plume produces the best fit to the measured data.

Figure $3 \mathrm{~b}$ shows that the best fit to the measured data occurs for a simulation when the total simulated mass is approximately $8 \times 10^{10} \mathrm{~kg}$. Plume height here does not appear to be as well constrained by inversion, although Fig. 3c shows that simulations with the lowest RMSE values tended to have heights below $20 \mathrm{~km}$. Likewise, inversions with diffusion coefficients from as low as 1 to as high as $1000 \mathrm{~m}^{2} \mathrm{~s}^{-1}$ gave similar goodness-of-fit values (Fig. 3d).

Median particle size was better constrained (Fig. 3e) with the best fit found using sizes between 1 and 0 phi. Mean wind speeds, calculated by averaging the wind profile at all heights, also varied greatly between inversion runs, with the lowest RMSE values using mass PDF 4 found for speeds between approximately 50 and $70 \mathrm{~m} \mathrm{~s}^{-1}$.

Concluding for phase A that the lowest RMSE values occurred when using mass PDF 4, we considered the 100 inversions carried out for this mass PDF and further investigated simulated eruption mass and plume height. For phase A, an additional constraint was imposed whereby only inversions with accumulation equal to or exceeding $1 \mathrm{~kg} \mathrm{~m}^{-2}$ at Hongo were considered acceptable. This avoided inversions that converged successfully to replicate measured accumulation close to source but that were less accurate at distal locations where fewer data points were available.

Inversion results are presented in a grid (Fig. 4) with the lowest RMSE value for each erupted mass and plume height 

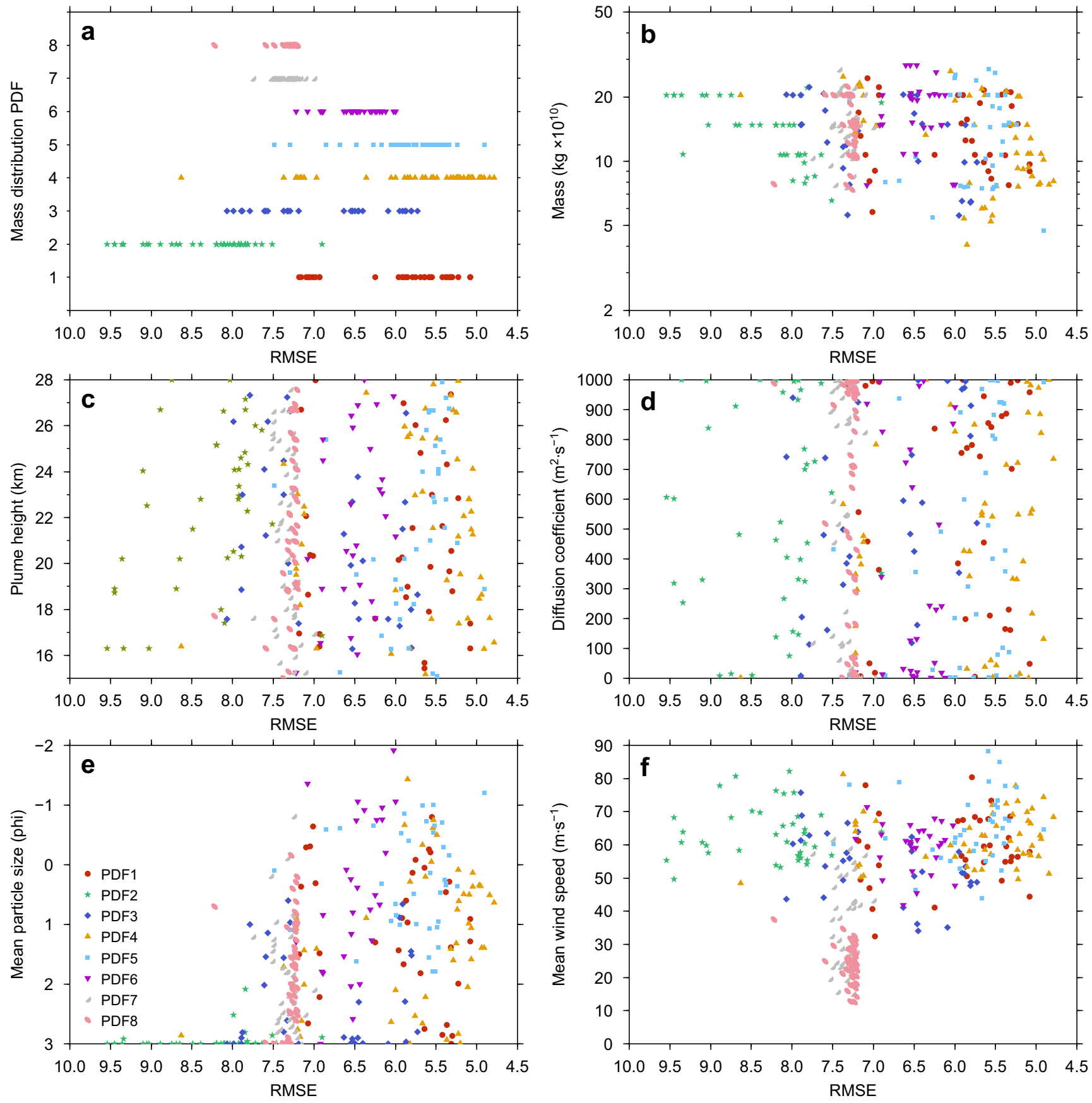

Fig. 3 Inversion results versus calculated root mean squared error (RMSE) for critical eruption parameters. Results include each PDF of mass distribution within the plume, erupted mass and plume height

combination. For each combination, only the inversion with the lowest RMSE of the ten modelled seeds is included. Colours represent the eight PDFs describing mass distribution

range combination shown by a circle (mass $\geq 1 \mathrm{~kg} \mathrm{~m}^{-2}$ at Hongo) or cross $\left(<1 \mathrm{~kg} \mathrm{~m}^{-2}\right.$ at Hongo) at the location determined to be the best fit to the measured data. Where the erupted mass range is less than $5.6 \times 10^{10} \mathrm{~kg}\left(10^{10.75} \mathrm{~kg}\right)$, the mass chosen by inversion is always near the top limit of the considered range. Likewise, for erupted mass ranges higher than $1.07 \times 10^{11}\left(10^{11.03} \mathrm{~kg}\right)$, inversion tended to choose a mass value near the lower limit of the range considered. Low RMSE values were calculated for plume heights between

16.3 and $22.8 \mathrm{~km}$. Consistent with these observations, the best inversion results indicated a mass of $7.8 \times 10^{10} \mathrm{~kg}$ and plume height of $17.6 \mathrm{~km}$.

\section{Phase inversions}

For each simulated phase, the inversion exhibiting the lowest RMSE was selected and the corresponding source parameters, 


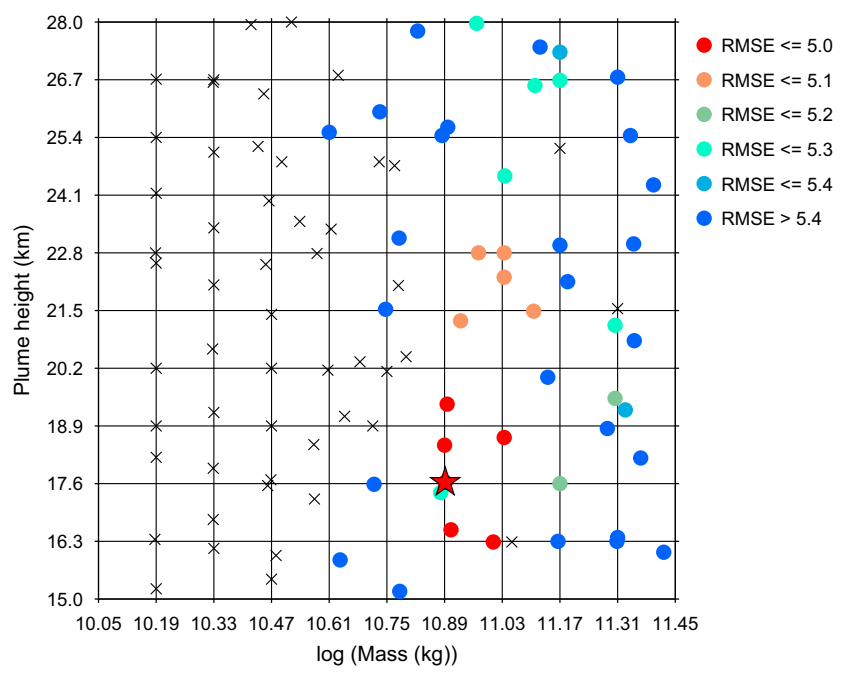

Fig. 4 Using PDF 4 to describe particle release from eruption plume, phase A inversion results for each plume height and total eruptive mass combination. Colours represent the RMSE, with the simulation represented by the lowest RMSE shown by a red star. Black crosses represent simulations where accumulation at Hongo was less than $1 \mathrm{~kg} \mathrm{~m}^{-2}$

model coefficients and meteorological conditions determined through inversion (Table 2) were modelled over a 1-km resolution grid using the forward solution of Tephra2. Isomass maps were constructed using these simulations and the measured and simulated tephra accumulation at measurement points were compared using linear regression (selected examples are shown in Fig. 5 with all remaining phases in
Fig. 5 Forward simulation results utilising parameters determined by inverting phases $\mathrm{A}, \mathrm{C}, \mathrm{H}$ and $\mathrm{P}$. Key results for remaining phases are presented in Table 2 and figures can be found in supplementary material. Isomass maps $\left(\mathrm{kg} \mathrm{m}^{-2}\right)$ for the forward solution of calculated eruptive parameters are shown on the left. Sample locations from Miyaji et al. (2011) are shown by solid circles. On the right, measured accumulation is plotted against simulated accumulation for each measurement point. The dotted line represents a correlation of 1 and the solid line represents the line of best fit between measured and simulated accumulation. The equation of best-fit line $(y)$ and correlation coefficient $(r)$ are indicated on each plot

supplementary information). Summary regression results for each phase are given in Table 3.

Considering again phase $\mathrm{A}$, the regression plot (top right Fig. 5) compares the simulated and measured accumulation for each of the 69 locations considered and results in a correlation coefficient of 0.97 . The slope of 0.90 ( $95 \%$ confidence interval $0.85,0.95$ ) is less than 1 and therefore implies that the inversion generally tends to underestimate measured accumulation. We are particularly interested in the tephra accumulation simulated for distal areas including the now heavily populated area of central Tokyo. For phase A, Miyaji and Koyama (2011) gave a value of $2 \mathrm{~kg} \mathrm{~m}^{-2}$ at Hongo, and Miyaji et al. (2011) gave $5 \mathrm{~kg} \mathrm{~m}^{-2}$ on the Boso Peninsula in western Chiba (locations most distal to source as shown in top left Fig. 5). Corresponding values determined by inversion were 1.1 and $1.3 \mathrm{~kg} \mathrm{~m}^{-2}$, respectively. Although not available, a larger number of measured accumulation points in more distal areas would likely improve results further from source.

Table 2 Best-fit eruption parameters, coefficients and wind characteristics, as determined by inversion, for each phase of the Hoei eruption and for the total eruption sequence

\begin{tabular}{|c|c|c|c|c|c|c|c|}
\hline Group & Phase & Mass $\left(\times 10^{10} \mathrm{~kg}\right)$ & $\begin{array}{l}\text { Plume height } \\
(\mathrm{km})\end{array}$ & Mass PDF & $\begin{array}{l}\text { Median particle } \\
\text { size (phi) }\end{array}$ & $\begin{array}{l}\text { Diffusion coefficient } \\
\left(\mathrm{m}^{2} \mathrm{~s}\right)\end{array}$ & $\begin{array}{l}\text { Mean wind speed } \\
\left(\mathrm{m} \mathrm{s}^{-1}\right)\end{array}$ \\
\hline \multirow[t]{2}{*}{ I } & A & 7.8 & 17.6 & 4 & 0.5 & 1000 & 51.2 \\
\hline & B & 4.5 & 20.9 & 2 & -3.0 & 80 & 62.3 \\
\hline \multirow[t]{4}{*}{ II } & $\mathrm{C}$ & 28.5 & 18.0 & 6 & -0.9 & 745 & 66.1 \\
\hline & $\mathrm{D}$ & 8.2 & 17.1 & 1 & 1.2 & 912 & 57.9 \\
\hline & E & 18.6 & 11.5 & 5 & 2.5 & 485 & 71.4 \\
\hline & $\mathrm{F}$ & 11.5 & 16.0 & 4 & 2.9 & 306 & 48.9 \\
\hline \multirow[t]{7}{*}{ III } & G & 1.8 & 9.4 & 1 & -1.4 & 785 & 77.8 \\
\hline & $\mathrm{H}$ & 24.1 & 15.9 & 4 & 1.1 & 193 & 66.4 \\
\hline & I & 12.0 & 15.6 & 1 & 1.4 & 230 & 59.5 \\
\hline & $\mathrm{J}$ & 11.0 & 13.1 & 4 & 0.8 & 995 & 66.6 \\
\hline & K & 2.7 & 11.3 & 3 & -0.4 & 506 & 62.1 \\
\hline & $\mathrm{L}$ & 15.9 & 16.1 & 5 & -0.8 & 121 & 71.6 \\
\hline & M & 8.2 & 10.3 & 6 & 2.6 & 711 & 49.0 \\
\hline \multirow[t]{4}{*}{ IV } & $\mathrm{N}$ & 11.9 & 19.0 & 1 & -1.1 & 961 & 72.6 \\
\hline & $\mathrm{O}$ & 10.3 & 10.3 & 4 & 1.0 & 158 & 54.0 \\
\hline & $\mathrm{P}$ & 8.5 & 13.1 & 5 & 0.7 & 813 & 60.2 \\
\hline & Q & 23.6 & 13.5 & 6 & -1.2 & 270 & 74.1 \\
\hline \multicolumn{2}{|c|}{ Hoei sequence (HS) } & 168.8 & 10.0 & 5 & 3.0 & 478 & 49.6 \\
\hline
\end{tabular}



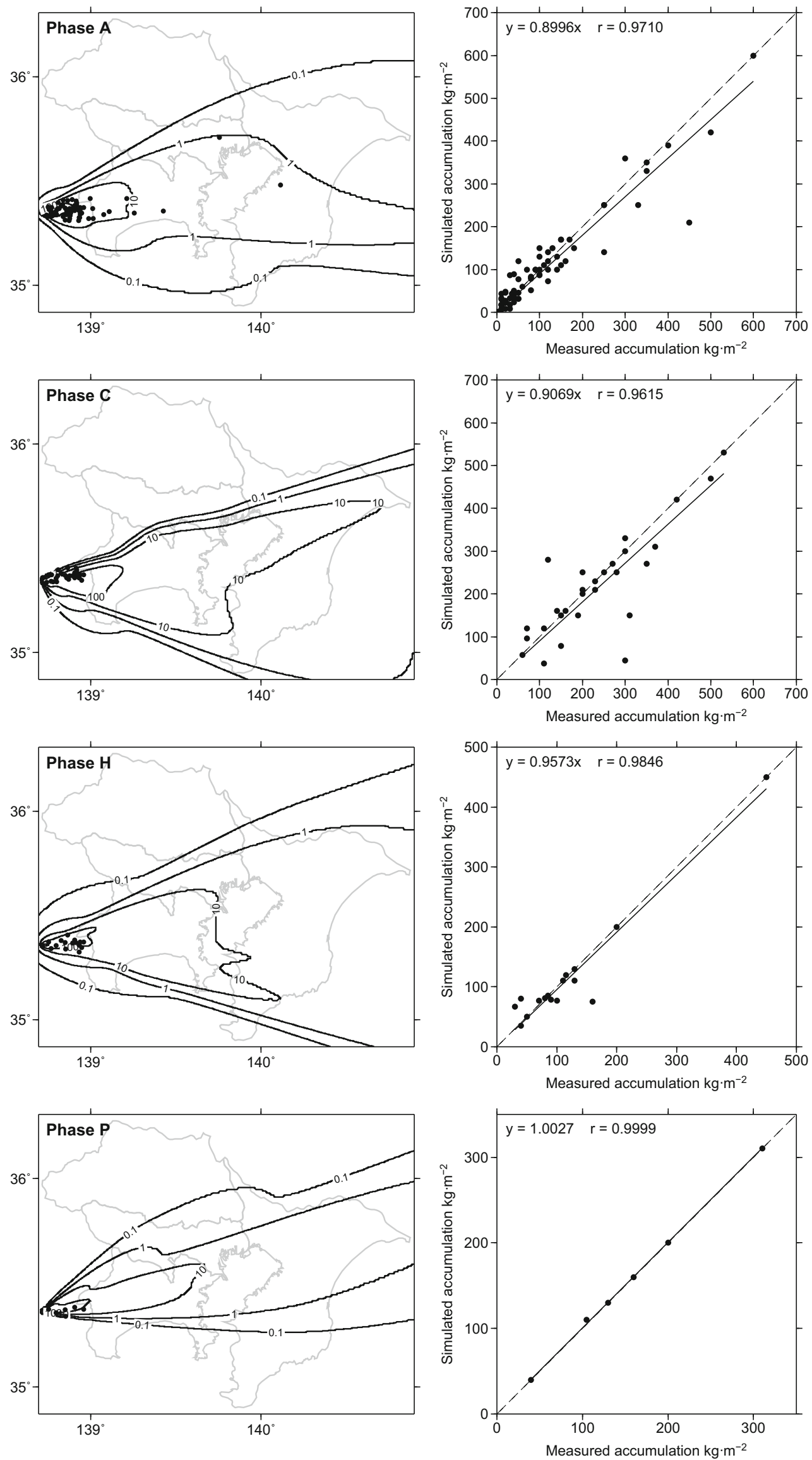
Table 3 Values calculated when analysing the statistical significance between measured and simulated accumulation for each phase of the Hoei eruption and the total eruption sequence

\begin{tabular}{|c|c|c|c|c|c|c|c|c|}
\hline Group & Phase & $\begin{array}{l}\text { Number } \\
\text { of points }\end{array}$ & Slope & $\begin{array}{l}\text { Correlation } \\
\text { coefficient }\end{array}$ & $\begin{array}{l}\text { Slope lower } 95 \% \\
\text { limit }\end{array}$ & $\begin{array}{l}\text { Slope upper } 95 \% \\
\text { limit }\end{array}$ & $\begin{array}{l}\text { Number of positive } \\
\text { residuals }\end{array}$ & $\begin{array}{l}\text { Number of negative } \\
\text { residuals }\end{array}$ \\
\hline \multirow[t]{2}{*}{ I } & A & 69 & 0.90 & 0.97 & 0.85 & 0.95 & 29 & 30 \\
\hline & B & 35 & 1.00 & 1.00 & 0.97 & 1.02 & 19 & 10 \\
\hline \multirow[t]{4}{*}{ II } & $\mathrm{C}$ & 28 & 0.91 & 0.96 & 0.80 & 1.01 & 11 & 8 \\
\hline & $\mathrm{D}$ & 18 & 1.00 & 0.99 & 0.93 & 1.08 & 7 & 5 \\
\hline & $\mathrm{E}$ & 19 & 0.97 & 0.98 & 0.89 & 1.06 & 7 & 5 \\
\hline & $\mathrm{F}$ & 23 & 1.01 & 0.99 & 0.94 & 1.07 & 6 & 5 \\
\hline \multirow[t]{7}{*}{ III } & G & 17 & 0.99 & 0.99 & 0.90 & 1.08 & 7 & 5 \\
\hline & $\mathrm{H}$ & 16 & 0.96 & 0.98 & 0.86 & 1.05 & 5 & 5 \\
\hline & I & 14 & 0.92 & 0.98 & 0.79 & 1.04 & 3 & 3 \\
\hline & $\mathrm{J}$ & 14 & 0.99 & 1.00 & 0.96 & 1.02 & 5 & 3 \\
\hline & $\mathrm{K}$ & 18 & 0.94 & 0.96 & 0.80 & 1.07 & 4 & 7 \\
\hline & $\mathrm{L}$ & 24 & 0.97 & 0.97 & 0.87 & 1.07 & 9 & 9 \\
\hline & M & 22 & 0.96 & 0.99 & 0.89 & 1.02 & 7 & 7 \\
\hline \multirow[t]{4}{*}{ IV } & $\mathrm{N}$ & 17 & 0.95 & 0.98 & 0.86 & 1.04 & 4 & 6 \\
\hline & $\mathrm{O}$ & 9 & 1.00 & 1.00 & 1.00 & 1.00 & 0 & 0 \\
\hline & $\mathrm{P}$ & 6 & 1.00 & 1.00 & 0.99 & 1.02 & 0 & 1 \\
\hline & Q & 4 & 1.00 & 1.00 & 1.00 & 1.00 & 0 & 0 \\
\hline \multicolumn{2}{|c|}{ Hoei sequence (HS) } & 101 & 0.83 & 0.89 & 0.74 & 0.91 & 51 & 44 \\
\hline
\end{tabular}

Phase C began at approximately 17:00 on 16th December with activity lasting around $8 \mathrm{~h}$. This period of activity was characterised by hot incandescent bombs that caused the fires in Suyama, $13 \mathrm{~km}$ from the vent. Phase C exhibited the largest erupted mass as estimated by Miyaji et al. (2011) $(2.6 \times$ $\left.10^{11} \mathrm{~kg}\right)$ and as determined by inversion $\left(2.85 \times 10^{11} \mathrm{~kg}\right)$. The resulting regression line has a slope of $0.91(95 \%$ confidence interval $0.80,1.01)$ and a correlation coefficient of 0.96 . Although this shows an excellent correspondence between simulated and measured values, the slope of less than 1.0 may again suggest that the inversion generally underestimated mass for the 28 points considered.

Inversion of phase $\mathrm{H}$ resulted in the next highest estimation of mass for a single phase $\left(2.41 \times 10^{11} \mathrm{~kg}\right)$, higher than the $1.4 \times 10^{11} \mathrm{~kg}$ estimated by Miyaji et al. (2011). The onset of unit $\mathrm{H}$ has been correlated with ash fall in Edo (Miyaji et al. 2011) and inversion results agreed, with accumulation ranging between 1 and $10 \mathrm{~kg} \mathrm{~m}^{-2}$ over central Tokyo. Inversion provided a very good fit to the measured data with a slope of 0.96 (95\% confidence interval $0.86,1.05$ ) and correlation coefficient of 0.98 .

It was suggested by Miyaji et al. (2011) that phase P, with relatively coarse scoria, may have resulted from a higher plume and been associated with ash fall in Edo. This phase began at 10:30 on the 27th and lasted $11.5 \mathrm{~h}$; however, the unit can only be distinguished in six locations. Similarly, units O and $\mathrm{Q}$ are only identified in nine and four locations, respectively. Because of the low number of observations, and despite the almost perfect correlation between measured and simulated mass (e.g. bottom right Fig. 5), it is difficult to have a high level of confidence in the results from these phases.

Summing the mass calculated by inverting each phase gives a total erupted mass for the Hoei eruption of $2.09 \times$ $10^{12} \mathrm{~kg}$. Source parameters determined by inversion for individual phases are shown in Table 2 and will be discussed in the following sections.

\section{Hoei sequence as one inversion}

The observations above show that, where enough data are available, inversion and the Tephra 2 model can successfully replicate individual eruptive phases where eruptive and meteorological parameters remain relatively constant for periods of hours to days. We then investigated whether this methodology is appropriate for simulating an entire eruptive sequence. This has important consequences for probabilistic long-term hazard modelling, where modelling an eruption as a single event is more computationally efficient than modelling multiple eruptive phases.

Phases A through Q were deposited over a period of 16 days and data describing the deposit as a whole are available for 101 locations that extend as far north as Hongo and east into Chiba prefecture (Miyaji et al. 2011). The total mass for the eruptive sequence was estimated by Miyaji et al. (2011) to be between $1.72 \times 10^{12}$ and $1.92 \times 10^{12} \mathrm{~kg}$ and we allowed 

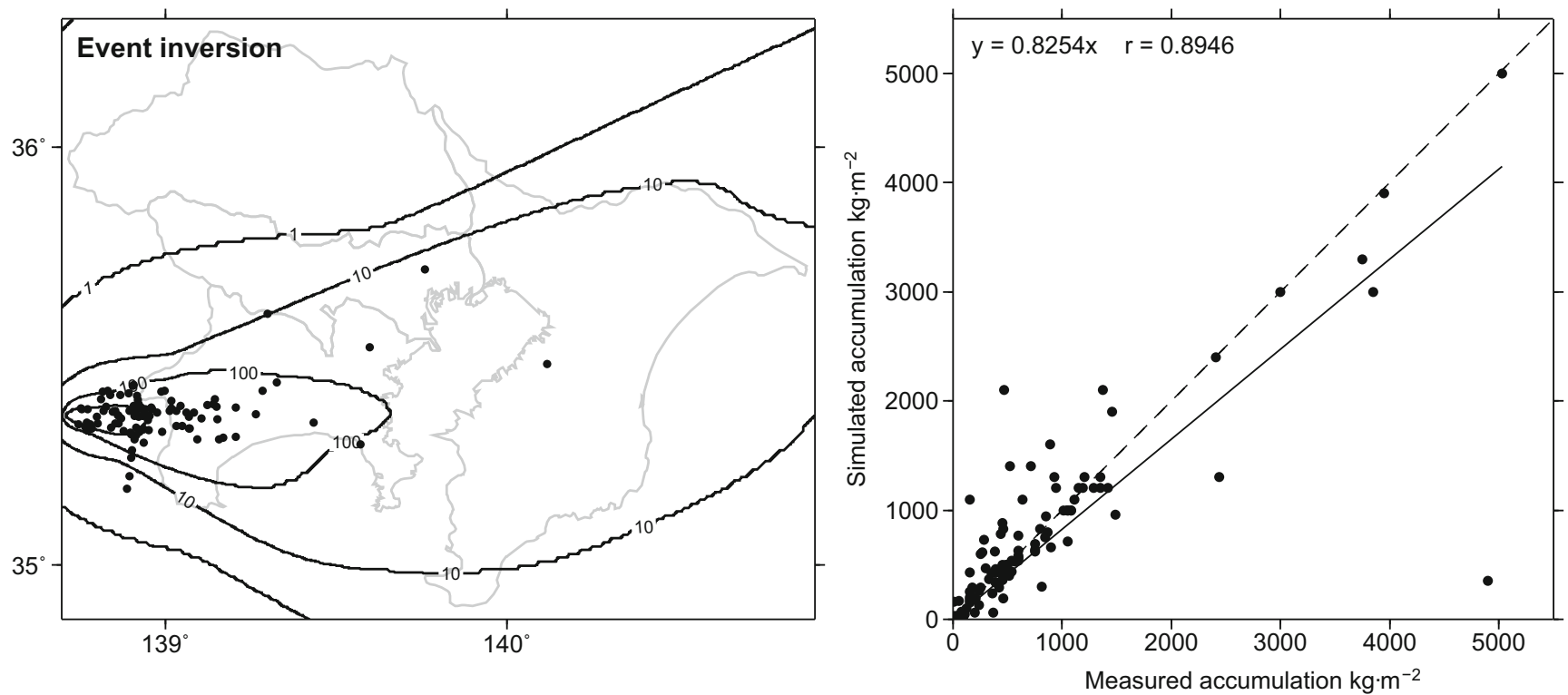

Fig. 6 Inversion results from the best-fit simulation of the entire eruptive sequence. Isomass map $\left(\mathrm{kg} \mathrm{m}^{-2}\right)$ for the forward solution of calculated eruptive parameters is shown on the left. Sample locations from Miyaji et al. (2011) are shown by solid circles. The inner isomass contour is not annotated but represents $1000 \mathrm{~kg} \mathrm{~m}^{-2}$ extent. On the right, measured

our inverted mass for HS to range more widely between $3.6 \times$ $10^{11}$ and $9 \times 10^{12} \mathrm{~kg}$. Simulated maximum plume heights ranged between 8 and $28 \mathrm{~km}$. The forward solution and accumulation regression for the best simulation are shown in Fig. 6. The regression shows a slope of 0.83 ( $95 \%$ confidence interval $0.74,0.91$ ) and a correlation coefficient of 0.89 .

This slope and correlation show a poorer fit between measured and simulated accumulation than for any individual phase. However, the larger number of available data points contributes to this observation. The slope of less than 1.0 again suggests that inversion may in general underestimate mass at the points considered. Inversion for one point, $3 \mathrm{~km}$ southeast of the simulated vent, predicted a total accumulation of $350 \mathrm{~kg} \mathrm{~m}^{-2}$ despite the total deposit being measured at $4900 \mathrm{~kg} \mathrm{~m}^{-2}$ in this location. This may indicate that inversion had difficulty replicating the deposit where tephra would have fallen relatively quickly from the plume, or that the changing and uncertain vent location, not accounted for here, played an important role in the thick deposit at this location. In addition, discrepancies are noted for two locations to the southeast of the $10 \mathrm{~kg} \mathrm{~m}^{-2}$ contour (Fig. 6), approximately 22-24 km southeast of the vents. The measured accumulation for these points are, from north to south, 90 and $60 \mathrm{~kg} \mathrm{~m}^{-2}$, with inverted accumulation less at 6.9 and $3.4 \mathrm{~kg} \mathrm{~m}^{-2}$, respectively. This suggests that this particular inversion had difficulty replicating lobes of tephra away from the main dispersal axis.

The total erupted mass determined for HS was $1.69 \times$ $10^{12} \mathrm{~kg}$, less than the $2.09 \times 10^{12} \mathrm{~kg}$ estimated by summing the masses for each phase calculated by inversion. The maximum plume height calculated by inversion was $10 \mathrm{~km}$. A

accumulation is plotted against simulated accumulation for each measurement point. The dotted line represents a correlation of 1 and the solid line represents the line of best fit between measured and simulated accumulation

mass PDF of 5 (highest concentration of mass at the midsection of the plume) was found to best replicate the data with a median particle size of $3.0 \mathrm{phi}(0.125 \mathrm{~mm})$ and a mean wind speed of $49.6 \mathrm{~m} \mathrm{~s}^{-1}$ (Table 2).

By summing the forward solutions of each inverted phase, we can compare the total deposit simulated by considering each phase individually and by inverting data describing the entire eruptive sequence (Fig. 7). As deposit density was assumed to be $1000 \mathrm{~kg} \mathrm{~m}^{-3}$, the isomass maps constructed can in turn be compared directly to isopachs drawn by Miyaji et al. (2011) (Fig. 1).

Figure 7 shows that combining individual phases gives a more elongated simulated deposit, with contours also wider and extending further north into Tokyo. When combining simulated phases, inversion produced contours that are similar to those deduced directly from geological and eyewitness reports, although contours are not as elongated and 10 and $20 \mathrm{~mm} / \mathrm{kg} \mathrm{m}^{-2}$ contours do not extend as far to the north (see Figs. 1 and 7). This is likely due to the limited number of measured points available at distal locations for individual phases, which may have resulted in inversion underestimating accumulation further from source.

\section{Correlation between simulated and measured accumulation}

Of the regressions comparing simulated and measured accumulation presented above and in the supplementary information, all resulted in slopes that, although close to unity, were 


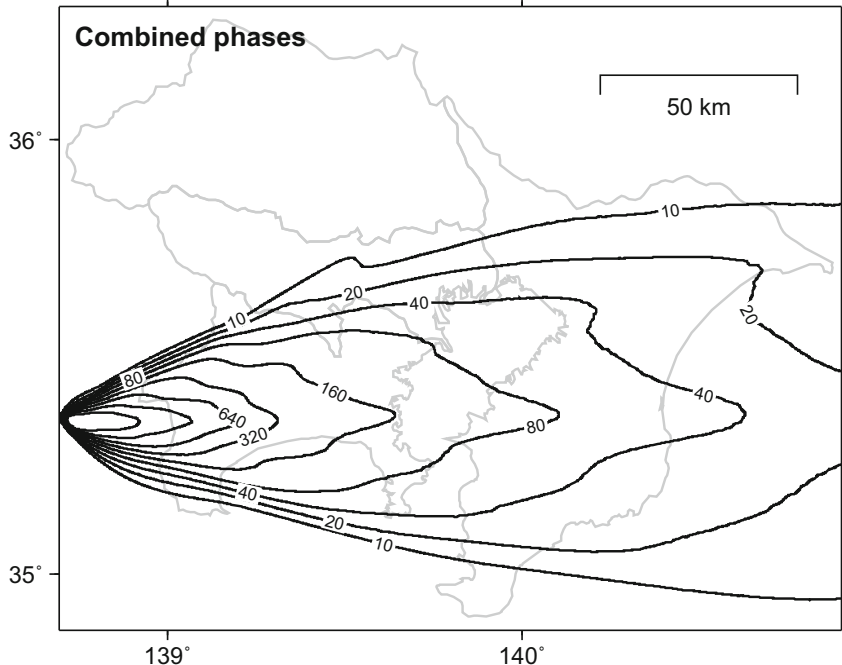

Fig. 7 Comparison of isomass maps $\left(\mathrm{kg} \mathrm{m}^{-2}\right)$ for individual phases, combined by summing the mass calculated at each grid point in the forward solutions, and inversion of the entire deposit. Inner isomass contours are not annotated but represent 1280 and $2560 \mathrm{~kg} \mathrm{~m}^{-2}$ extents.

generally less than or equal to 1.0 (Table 3 ). This suggests that the simulated mass is generally less than the measured mass for the locations considered and, in general, that inversion tended to underestimate measured values. The lowest slopes are seen for phase A (0.90) and HS (0.83) with corresponding correlation coefficients of 0.97 and 0.83 . For all regressions, $p$ values are less than 0.001 and therefore highly significant. To increase our confidence in the results, we considered the statistical significance of these regressions, with the results summarised in Table 3.

For all regressions, excluding A and HS, a slope of 1.0 falls within $95 \%$ confidence bounds, and we thus conclude that these slopes are not significantly different from unity. For a $95 \%$ confidence level, phase A resulted in a slope between 0.85 and 0.95 and HS between 0.74 and 0.91 . For these examples, we may assume that the best inverted simulation generally underestimated tephra accumulation for the locations considered. We thus explored A and HS further to see if this was caused by outliers or was a true product of the inversion methodology.

The Wilcoxon signed-rank test (Wilcoxon 1945; Siegel 1956) is a non-parametric statistical test used to compare matched samples to assess whether their population mean ranks differ (i.e. a paired difference test). In this case, the measured and simulated samples were matched for each observed point. This test assesses the impact of outliers on the slope of the regressions as it is based on the ranks of the differences, rather than on the magnitude of the differences.

For phase A, there is a greater number of negative than positive residuals (Table 3 ), indicating that the simulated mass is more often higher than that measured (Connor and Connor 2006). We set a null hypothesis that there is no difference

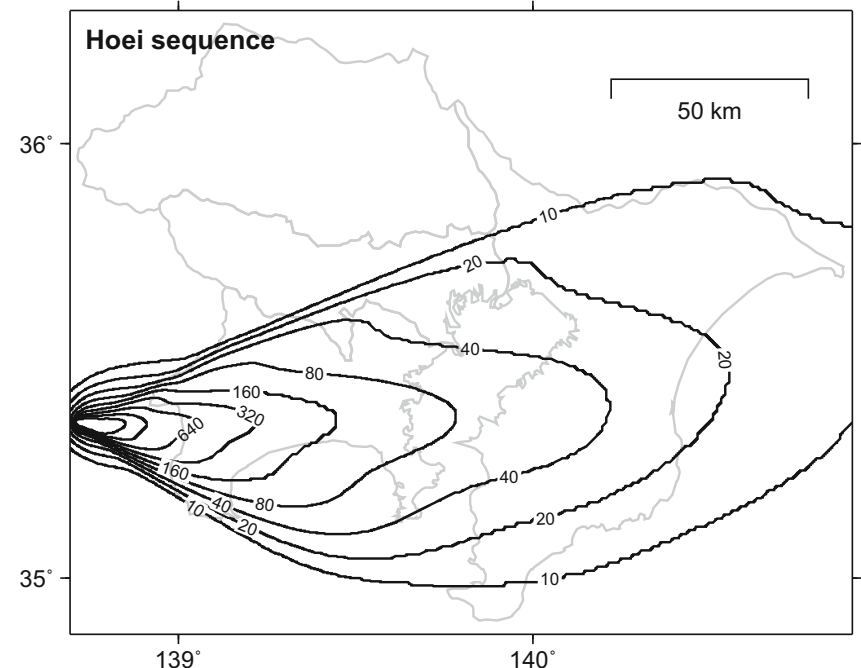

Isomass contour intervals are the same as those in Fig. 1 to allow easy comparison of the thickness estimated by Miyaji et al. (2011); as both studies assumed a density of $1000 \mathrm{~kg} \mathrm{~m}^{-3}$, the contours in Fig. 1 can be considered to represent both thickness $(\mathrm{mm})$ and mass in $\left(\mathrm{kg} \mathrm{m}^{-2}\right)$

between the measured and simulated tephra accumulation values against a two-sided alternative.

We calculated $T$, the sum of the ranks of the positive residuals, for phase A to be 866 . The sample size $(n)$ was reduced by the number of cases in which the measured and simulated values were equal. Here, the sample size was large and $T$ may be approximated by a normal distribution where the expected value of $T$ could be calculated as (Siegel 1956):

$E(T)=\frac{n(n+1)}{4}$

and the variance as:

$\operatorname{Var}(T)=\frac{n(n+1)(2 n+1)}{24}$

For phase $\mathrm{A}, n=59, E(T)=885$ and $\operatorname{Var}(T)=17,553$. The $Z$ variable could then be calculated as:

$Z=\frac{T-E(T)}{\sqrt{\operatorname{Var}(T)}}$

$Z$ was found to be -0.15 (i.e. $p>0.8$ ), and we therefore cannot reject the null hypothesis that measured and simulated values are equal; we conclude that the slope of the regression line may be influenced by additional outliers. This is shown in Fig. 5 with measured points $>200 \mathrm{~kg} \mathrm{~m}^{-2}$ clearly affecting the slope of the regression line.

For HS, there is a greater number of positive than negative residuals suggesting that simulated mass is more often lower than that measured. Assuming the same hypothesis as for A that there is no difference between measured and simulated tephra accumulation values against a two-sided alternative, $T$ 
is equal to $2182, n=95, E(T)=2280$ and $\operatorname{Var}(T)=72,580$. The $Z$ value was calculated to be $-0.36(p>0.7)$, and we can therefore not reject the null hypothesis that measured and simulated values are equal. As with phase A, outliers may affect the slope of the regression line for the HS inversion.

\section{Discussion}

\section{Total erupted mass}

Given sufficient input arguments, inversion appears to converge when predicting erupted mass. Combining individual phases gives a total erupted mass for the Hoei eruption of $2.09 \times$ $10^{12} \mathrm{~kg}$ and the HS simulation a mass of $1.69 \times 10^{12} \mathrm{~kg}$. Next, we compared those values with various curve-fitting techniques utilising the areas of the isomass contours deduced by Miyaji et al. (2011) (Table 4; Fig. 8). So that each method could be compared directly, a normalised root mean square error (NRMSE) was calculated describing the fit between measured and simulated or fitted tephra accumulations over all distances (Table 4).

We first utilised the exponential method proposed by Pyle (1989), where accumulation is assumed to decay exponentially with the square root of the area enclosed by the isomass contours. This method was recommended by Fierstein and Nathenson (1992) and utilised by Miyaji et al. (2011) to previously estimate total erupted mass from the Hoei eruption. These latter authors used two exponential curves to describe the thinning of the entire eruption sequence and individual phases. To account for a lack of distal data for phases B-Q, the slope of the distal curve for the entire deposit was combined with available proximal data so that a total mass could be approximated for each phase (Fig. 9). We also adopted this methodology, fitting two curves to the entire sequence and to phases $\mathrm{A}$ and $\mathrm{B}$, then adopting distal information from the entire sequence to approximate distal mass for phases $\mathrm{C}-\mathrm{Q}$. These revised calculations gave a combined mass for all phases of $2.52 \times 10^{12} \mathrm{~kg}$ and, utilising only HS contours, a mass of $1.59 \times 10^{12} \mathrm{~kg}$.

Fitting only one exponential curve to each phase (Table 4) gave a significantly lower total mass of $7.0 \times 10^{11} \mathrm{~kg}$, highlighting the lack of distal data for individual phases and the importance in considering distal tephra in total mass calculation. This is in agreement with previous studies, including Fierstein and Nathenson (1992), Pyle (1995), Bonadonna and Houghton (2005) and Bonadonna and Costa (2012), who state that volume may be significantly underestimated using the exponential method when distal data are missing. This must be balanced with uncertainty introduced due to subjective

Table 4 Erupted mass $\left(\times 10^{10} \mathrm{~kg}\right)$ calculated by inversion, exponential two-segment, exponential one-segment, power-law and Weibull methods. Number of isopachs used for curve fitting as presented in Miyaji et al. (2011)

\begin{tabular}{|c|c|c|c|c|c|c|c|}
\hline Group & Phase & Number of isopachs & Inversion & Exponential (two segments) & Exponential (one segment) & Power law & Weibull \\
\hline \multirow[t]{2}{*}{ I } & A & 6 & $7.8(6.9)$ & $5.7(5.0)$ & $5.0(18.4)$ & $8.5(1.1)$ & $5.8(1.7)$ \\
\hline & $\mathrm{B}$ & 6 & $4.5(1.3)$ & $2.6(0.4)$ & $2.5(18.6)$ & $4.3(5.0)$ & $6.0(3.1)$ \\
\hline \multirow[t]{4}{*}{ II } & $\mathrm{C}$ & 3 & $28.5(15.5)$ & $33.8(4.3)$ & $8.5(4.3)$ & $41.1(2.9)$ & - \\
\hline & $\mathrm{D}$ & 4 & $8.2(3.8)$ & $23.7(4.2)$ & $5.8(4.2)$ & $38.9(12.9)$ & $5.1(0.9)$ \\
\hline & $\mathrm{E}$ & 3 & $18.6(9.1)$ & $17.7(7.5)$ & $4.4(7.5)$ & $29.5(0.6)$ & - \\
\hline & $\mathrm{F}$ & 2 & $11.5(15.0)$ & $6.9^{*}$ & $1.8^{*}$ & $6.2 *$ & - \\
\hline \multirow[t]{7}{*}{ III } & G & 2 & $1.8(7.3)$ & $2.8^{*}$ & $0.7^{*}$ & $2.8^{*}$ & - \\
\hline & $\mathrm{H}$ & 3 & $24.1(6.3)$ & $18.5(8.8)$ & $4.7(8.8)$ & $19.0(1.2)$ & - \\
\hline & I & 3 & $12.0(13.2)$ & $9.4(0.2)$ & $2.5(0.2)$ & $9.2(5.3)$ & - \\
\hline & $\mathrm{J}$ & 3 & $11.0(2.8)$ & $16.8(3.7)$ & $4.3(3.7)$ & $28.2(3.4)$ & - \\
\hline & $\mathrm{K}$ & 4 & $2.7(11.8)$ & $9.0(5.1)$ & $2.4(5.1)$ & $5.7(11.4)$ & $2.3(4.8)$ \\
\hline & $\mathrm{L}$ & 3 & $15.9(8.8)$ & $24.9(1.9)$ & $6.4(1.9)$ & $20.9(3.4)$ & - \\
\hline & M & 3 & $8.2(7.9)$ & $6.0(4.7)$ & $1.7(4.7)$ & $2.9(0.1)$ & - \\
\hline \multirow[t]{4}{*}{ IV } & $\mathrm{N}$ & 3 & $11.9(6.2)$ & $14.5(0.6)$ & $3.9(0.6)$ & $27.0(5.5)$ & - \\
\hline & $\mathrm{O}$ & 2 & $10.3(0.0)$ & $18.1^{*}$ & $4.5^{*}$ & $16.3^{*}$ & - \\
\hline & $\mathrm{P}$ & 2 & $8.5(0.8)$ & $15.7^{*}$ & $3.9^{*}$ & $18.8^{*}$ & - \\
\hline & Q & 2 & $23.6(0.0)$ & $26.1^{*}$ & $7.1^{*}$ & $22.9^{*}$ & - \\
\hline \multicolumn{2}{|c|}{ Total A-Q } & & 209.1 & 252.3 & 70.0 & 302.1 & - \\
\hline \multicolumn{2}{|c|}{ Hoei sequence (HS) } & 9 & $168.8(11.2)$ & $158.8(2.4)$ & $161.1(21.8)$ & $190.4(4.5)$ & $154.3(11.1)$ \\
\hline
\end{tabular}

Normalised root mean square errors are given in brackets as percentages. Errors describe the fit of calculated tephra accumulation to measured points (inversion method) and isopachs derived from geological and historical data (other methods)

*Insufficient isopachs to determine normalised root mean square error

-Insufficient isopachs to determine mass from Weibull method 
Fig. 8 Erupted mass calculated for each phase of the Hoei eruption by inversion, exponential (two-segment), exponential (one-segment), power-law and Weibull methods. The Weibull method was applied to phases A, B, D and K, where a sufficient number of isopach areas were available
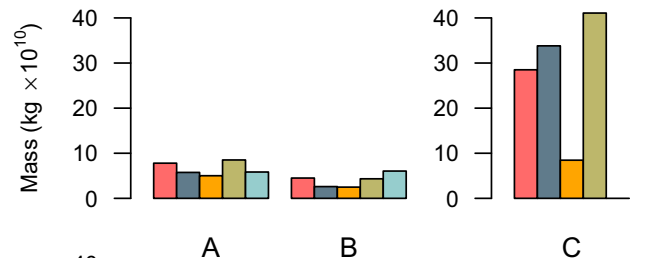

C

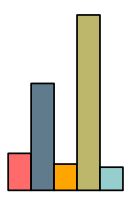

D

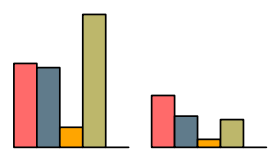

E

$\mathrm{F}$
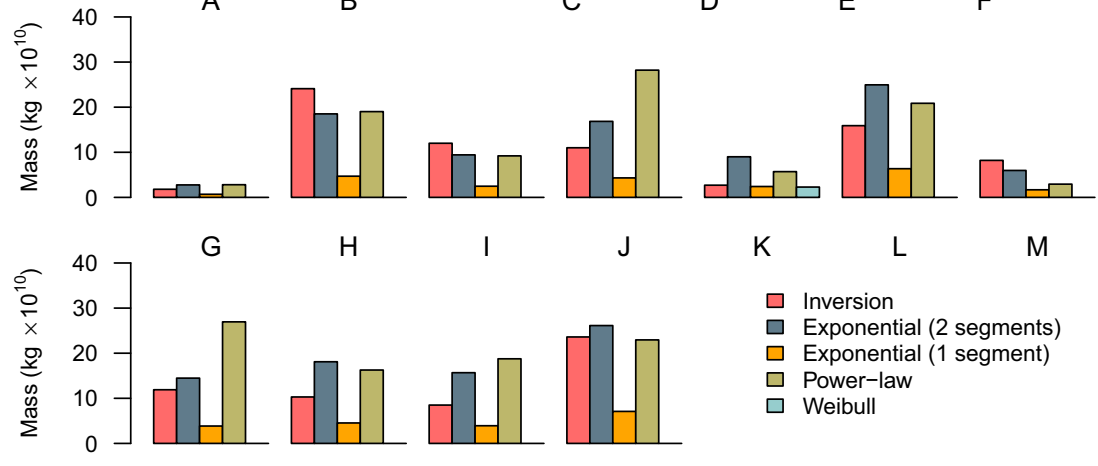

$\mathrm{H}$

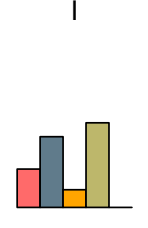

J

K

L

M

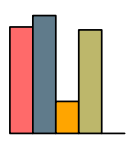

$\square$ Inversion

$\square$ Exponential (2 segments)

$\square$ Exponential (1 segment)

$\square$ Power-law

$\square$ Weibull
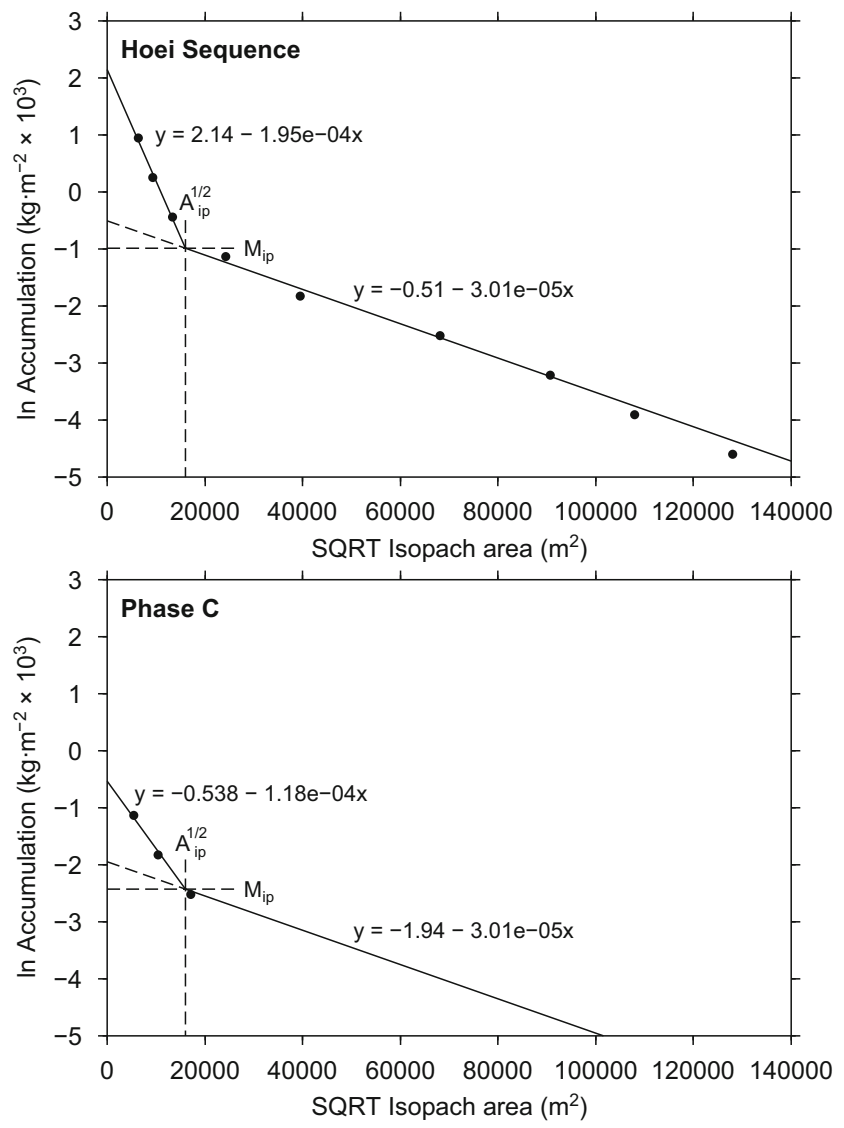

Fig. 9 Exponential (two-segment) method utilised by Miyaji et al. (2011) to calculate erupted mass for individual phases where distal data are missing. Using phase $\mathrm{C}$ as an example, distal mass was calculated considering the slope and intercept calculated for the entire Hoei sequence choices in the position and number of curves used for calculation when multiple curves are applied to describe dispersal data (Bonadonna and Costa 2012, 2013).

Fitting a power-law distribution to describe accumulation decay with the square root of area (Bonadonna and Houghton 2005) provides a more gradual thinning and may better approximate the true nature of deposits. However, depending on the power-law exponent, and, therefore, on the extent of the tephra deposit, this method has been shown to significantly overestimate total mass when proximal or distal data missing (Bonadonna and Houghton 2005; Bonadonna and Costa 2012, 2013). The same observation is made here with results being extremely sensitive to distal integration limits. Conservative limits were applied (100-200 km for phases where inverted mass was $\leq 1 \times 10^{11} \mathrm{~kg}$ and $150-250 \mathrm{~km}$ where mass was greater), but calculated total mass was typically greater than that determined by inversion and exponential methods (Table 4; Fig. 8).

The final method trialled was that proposed by Bonadonna and Costa $(2012,2013)$, where a Weibull curve was applied to the data. The Weibull function can be integrated between zero and infinity, shows more gradual thinning than the power-law distribution and is less sensitive to missing data (Bonadonna and Costa 2012, 2013). A minimum of three points is required for Weibull integration, but we found results to be unstable with fewer than four values. Therefore, this method was only used to estimate mass for phases A, B, D and K (Table 4; Fig. 8), and for HS (Table 4). Where sufficient data were available (phases A, B and HS), results were similar to those obtained from inversion and the two-segment exponential method. For phases D and K, a smaller mass in comparison to the exponential two-segment method potentially shows the importance of accounting for missing distal data. 
In summary, where enough data are available, the Weibull, exponential two-segment (accounting for distal data) and inversion methods for calculating mass are in good agreement. The exponential one-segment method tends to underestimate mass and the power-law method tends to overestimate (Fig. 8).

To further compare methods, we considered phase results for the exponential two-segment and inversion methods (Fig. 10). The slope of the regression is 0.79 ( $95 \%$ confidence interval $0.64,0.93$ ). This mirrors regressions for points describing individual phases, with inversion generally predicting smaller total mass than calculated by exponential curvefitting. However, we cannot conclude that this trend is significant.

\section{Plume height}

Inversion applied here determines time-averaged wind speed and direction for each layer, up to the maximum height of the plume, which results in simulated deposits that best replicate those measured. A constant range of wind speeds and directions are given as initial constraints and are not dependent on height within the plume, i.e. simulated wind speeds at the base of the plume are not necessarily lower than that nearer the top, as would be the case in reality. The shape of the deposit is controlled in part by the wind conditions at each level, rather than by varying conditions with time.

Miyaji et al. (2011) estimated total plume height and neutral buoyancy height based on magma heat flux

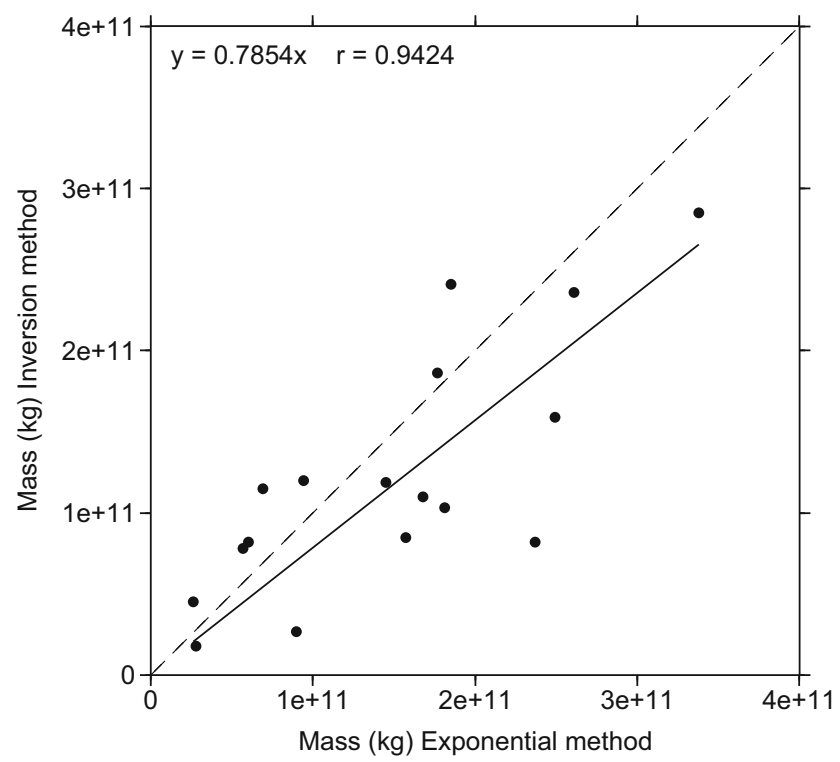

Fig. 10 Total eruptive mass calculated by inversion against mass calculated by exponential (two-segment) method. The dashed line represents a correlation of 1 between measured and simulated data. The solid line represents the line through the origin that best fits the data, with the equation for the line $(y)$ and correlation coefficient $(r)$ given in the top left corner relationships proposed by Woods (1988) (Table 1). Comparing maximum plume heights estimated by Miyaji et al. (2011) with those calculated by inversion gave a regression slope of 0.84 (95\% confidence interval $0.77,0.91)$ and a correlation coefficient of 0.99 ; comparing inversion results with neutral buoyancy estimates gave a slope of $1.08(95 \%$ confidence interval $1.00,1.17$ ) (data in Tables 1 and 2 , regression plot not shown). In all but seven cases, the plume height calculated by inversion was between the median values of maximum and neutral buoyancy height calculated by Miyaji et al. (2011). In five cases, inversion predicted heights less than the median neutral buoyancy height and in two cases higher than the median value of estimated maximum height. These results show that tephra dispersal is most accurately represented at all distances when the simulated maximum plume height is approximately equal to the estimated neutral buoyancy height.

As discussed for phase A, and as was the case for many of our inversion runs, similarly low RMSE values were calculated for simulations where mass was on the same scale as that calculated by the best inversion, but with plume heights that could vary by up to $5 \mathrm{~km}$. Other factors such as the PDF of mass within the plume, particle size distribution and wind conditions also interact with this parameter (see also Scollo et al. 2008) and, therefore, it cannot be well constrained. Similarly, Volentik et al. (2010) concluded that although inversion constrained erupted mass well, this was not the case for plume height; improvements were made by inverting for individual particle size classes, therefore removing uncertainty in particle size and fall velocity.

\section{Distribution of mass within plume}

The distribution of tephra within the plume was represented by a beta function describing the relative proportion of mass released from various relative heights within the plume (Eq. 2; Fig. 2). Rather than allowing inversion to select the function parameters, $\alpha$ and $\beta$, these were fixed and eight possible probability density functions (PDFs) were tested ranging from a uniform distribution to distributions with a more asymmetric release of material with towards the base or top of the plume. For each eruptive phase, a low RMSE indicates a preferential distribution of mass within the plume (see Fig. 3a as an example).

Only for phases D, G, I and N was a uniform distribution of mass in the plume (PDF 1) found to produce the best fit to the measured data. Phases E, L, P and HS were best replicated by PDF 5, where mass is concentrated at a mid-level in the plume. Phase B was best simulated by PDF 2, and phases A, $\mathrm{F}, \mathrm{H}, \mathrm{J}, \mathrm{K}$ and $\mathrm{O}$ were most accurately represented by assuming PDF 3 or 4 , with mass concentrated in the lower part of the plume. This is consistent with Fero et al. (2009) who suggested that for the 1991 Pinatubo eruption, the largest 
amount of ash may have been released at a height significantly lower than the maximum observed plume height, and Mannen (2014) who, for a sub-Plinian eruption, showed that most particles segregated from the lower section of the plume. However, as our maximum simulated plume heights were nearest to neutral buoyancy heights, tephra was predominately dispersed from heights lower than expected. Only for phases $\mathrm{C}, \mathrm{M}$ and $\mathrm{Q}$ were plumes with high concentrations of tephra in the upper part of the plume found to best replicate the observed deposit. Moreover, PDFs 7 and 8, where mass is concentrated highest in the plume, did not most accurately simulate any observed deposits.

We found no obvious relationship between the mass PDF determined to be optimal and phase duration or eruption rate. The PDF value was, however, positively correlated with mass, with higher volume phases, C and Q in particular, finding it preferential to have a larger amount of tephra in the higher portion of the plume. Considering both the inverted mass PDF and inverted plume height, the height at which most particles were released was between 2 and $12 \mathrm{~km}$ above the vent. Averaged across all phases, this was equal to $33 \%$ of the maximum plume height and $43 \%$ of the neutral buoyancy height estimated by Miyaji et al. (2011).

\section{Total particle size distribution}

A detailed analysis of the Hoei deposit at Dainichido, $7.5 \mathrm{~km}$ east of the vent, was undertaken by Miyaji et al. (2011). We compared the median particle size ( $\mathrm{mm}$ ) for each phase at this location with that calculated by our forward solutions at the same location and found a poor correlation (slope 1.11; $95 \%$ confidence interval $0.67,1.56$; correlation coefficient 0.67 ).

To further investigate, the mean particle size for the entire simulated deposit was compared to the calculated mass and plume height for each phase and to the duration of each phase with no clear relationships observed. There was, however, a weak positive correlation between mean wind speed and mean particle size with larger particle sizes being compensated for by faster wind speeds. Similar to plume height, and when inversion is based solely on mass accumulation, the particle size distribution cannot be well constrained as this distribution interacts with other parameters such as plume height, atmospheric diffusion and wind speed.

\section{Wind conditions}

Current long-term December mean wind speeds at Fuji Volcano were obtained from NCEP/NCAR reanalysis data provided by the NOAA/OAR/ESRL PSD, Boulder, Colorado, USA, from their Web site at http://www.esrl.noaa. gov/psd (Kalnay et al. 1996). These were found to be $31 \mathrm{~m} \mathrm{~s}^{-}$ 1 , averaged below approximately $26 \mathrm{~km}$, and $71 \mathrm{~m} \mathrm{~s}^{-1}$ at a height of approximately $12 \mathrm{~km}$. Considering an estimated 2-
$2.5 \mathrm{~h}$ for tephra to reach Edo following the sounds of explosions from Fuji volcano during the Hoei eruption (Miyaji et al. 2011), tephra would have been dispersed, on average, at between 11 and $14 \mathrm{~m} \mathrm{~s}^{-1}$, with the majority of time spent at lower altitudes with relatively slower wind speeds.

Independent from this information, inversion was used to estimate wind speed and direction for 10 atmospheric layers up to the maximum height of the plume. Wind speed was allowed to vary between 10 and $120 \mathrm{~m} \mathrm{~s}^{-1}$ and the range of sampled wind directions was determined from the extent of the deposits. For phase D, wind direction was varied between 225 and $340^{\circ}$; for all remaining phases, between 225 and $315^{\circ}$. Rather than replicating true wind conditions, this methodology utilises changes in wind direction and speed with height to most accurately simulate the deposit that may also have been influenced by changes in wind conditions with time. Therefore, the calculated wind profile for a given phase does not give a true representation of the wind conditions at the time of the eruption of that material, although it is interesting to look at averaged conditions and general trends.

Mean wind speeds averaged over the eruption plume (Table 2) ranged between 49 and $78 \mathrm{~m} \mathrm{~s}^{-1}$, which are higher than average conditions, but incorporate false maximums at some levels that helped to better replicate the deposit. Higher speeds did not only occur in the upper portion of the simulated plume but were randomly spread throughout. Future inversion investigations could consider fixing wind conditions; however, this may not be as successful in replicating pulses of activity in a discrete simulation.

\section{Conclusions}

Inversion modelling was carried out for the Hoei eruption of Fuji Volcano, which occurred over 15 days at the end of 1707. Documented eyewitness accounts and detailed geological investigations permit tephra accumulation to be accurately determined at a large number of locations for individual phases of the eruption. Inversion techniques were applied to replicate each tephra-producing phase of the eruption and the eruptive sequence as a whole.

Inversion exhibited a general trend to slightly underestimate the measured or observed accumulation for the locations considered. However, regression analysis of measured and simulated values and statistical significance testing of residuals showed that only phase $\mathrm{A}$, and the Hoei sequence as a single inversion, showed a significant tendency for inversion to underestimate measured values and that this may have been the result of outliers.

Inversion was found to converge well to predict total erupted mass; however, parameters such has plume height, distribution of mass within the plume, total particle size 
distribution and wind speed interacted so that we could be less confident with these estimations. The total mass estimated by inverting individual eruptive phases was $2.09 \times 10^{12} \mathrm{~kg}$ with $1.69 \times 10^{12} \mathrm{~kg}$ determined when considering a single data set describing the entire eruption sequence. These values were found to be most compatible with mass calculation using an exponential (two-segment) curve fitting approach. Using the areas of isopach contours developed by Miyaji et al. (2011) and accounting for missing distal data gave comparative values of $2.52 \times 10^{12}$ and $1.59 \times 10^{12} \mathrm{~kg}$. Using a Weibull fitting method also gave similar results for phases where enough data were available $\left(1.54 \times 10^{12} \mathrm{~kg}\right.$ for the total Hoei sequence).

Both inversion and exponential curve fitting methods applied to multiple combined phases resulted in a greater total mass being determined for the Hoei eruption compared to calculations considering a single set of data describing the Hoei sequence. The single inversion for the entire Hoei sequence produced a deposit that did not extend as far to the east or north. Inversion was found to be highly dependent on available measured or observed tephra accumulation data. In simulating for individual phases, detailed geological data close to source allowed for more accurate simulation of the deposit, taking into account subtleties such as lobes deposited during transient increases in eruption rate and variations in wind velocity or direction, which allowed for a more accurate representation of the deposit.

Acknowledgements The authors would like to sincerely thank Naomichi Miyaji for his detailed geological and historical investigations, without which this study would not have been possible. Toshitsugu Fujii provided valuable information regarding evidence for Hoei tephra at Hongo campus, which added important information for the simulations carried out here. We also wish to thank Tetsuya Okada for translation expertise, Valentina Koschatzky for helpful discussions over curve fitting techniques and John McAneney for review of an early draft. We are grateful for the detailed comments from two anonymous reviewers and from, editor, Judy Fierstein that allowed us to improve the manuscript.

Open Access This article is distributed under the terms of the Creative Commons Attribution 4.0 International License (http:// creativecommons.org/licenses/by/4.0/), which permits unrestricted use, distribution, and reproduction in any medium, provided you give appropriate credit to the original author(s) and the source, provide a link to the Creative Commons license, and indicate if changes were made.

\section{References}

Biass S, Bonadonna C (2012) A fast GIS-based risk assessment for tephra fallout: the example of Cotopaxi volcano, Ecuador - part I: probabilistic hazard assessment. Nat Hazards 65(1):497-521. doi:10. 1007/s11069-012-0378-z
Bonadonna C, Costa A (2012) Estimating the volume of tephra deposits: a new simple strategy. Geology 40(5):415-418. doi:10.1130/ G32769.1

Bonadonna C, Costa A (2013) Plume height, volume and classification of volcanic eruptions based on the Weibull function. Bull Volcanol 75: 742. doi:10.1007/s00445-013-0742-1

Bonadonna C, Houghton BF (2005) Total grainsize distribution and volume of tephra-fallout deposits. Bull Volcanol 67:441-456. doi:10. 1007/s00445-004-0386-2

Bonadonna C, Ernst GGJ, Sparks RSJ (1998) Thickness variations and volume estimates of tephra fall deposits: the importance of particle Reynolds number. J Volcanol Geotherm Res 81(3-4):173-187. doi: 10.1016/S0377-0273(98)00007-9

Bonadonna C, Macedonio G, Sparks RSJ (2002) Numerical modelling of tephra fallout associated with dome collapses and Vulcanian explosions: application to hazard assessment on Montserrat. In: Druitt TH, Kokelaar BP (eds) The eruption of Soufrière Hills Volcano, Montserrat, from 1995 to 1999 , Geological Society of London, Memoirs, 21. Geological Society of London, London, pp 517-537

Bonadonna C, Connor CB, Houghton BF, Connor LJ, Byrne M, Laing A, Hinks T (2005) Probabilistic modeling of tephra dispersal: hazard assessment for a multi-phase eruption at Tarawera, New Zealand. J Geophys Res 110:B03203. doi:10.1029/2003JB002896

Bonadonna C, Cioni R, Pistolesi M, Elissondo M, Baumann V (2015a) Sedimentation of long-lasting wind-affected volcanic plumes: the example of the 2011 rhyolitic Cordón Caulle eruption, Chile. Bull Volcanol 77(2):1-19. doi:10.1007/s00445-015-0900-8

Bonadonna C, Costa A, Folch A, Koyaguchi T (2015b) Tephra dispersal and sedimentation. In: Sigurdsson H, Houghton B, McNutt S, Rymer H, Stix J (eds) Encyclopedia of volcanoes, 2nd edn. Elsevier, pp 587-597

Bonadonna C, Pistolesi M, Cioni R, Degruyter W, Elissondo M, Baumann V (2015c) Dynamics of wind-affected volcanic plumes: the example of the 2011 Cordón Caulle eruption, Chile. J Geophys Res Solid Earth 120(4):2242-2261. doi:10.1002/2014JB011478

Bonasia R, Macedonio G, Costa A, Mele D, Sulpizio R (2010) Numerical inversion and analysis of tephra fallout deposits from the $472 \mathrm{AD}$ sub-Plinian eruption at Vesuvius (Italy) through a new best-fit procedure. J Volcanol Geotherm Res 189(3-4):238-246. doi:10.1016/j. jvolgeores.2009.11.009

Cabinet Office (2004) Report of the committee for hazard maps of Fuji Volcano. Cabinet Office, Tokyo (Japanese)

City of Odawara (1999) History of Odawara City — the early modern era City of Odawara, Odawara (Japanese)

Connor LJ, Connor CB (2006) Inversion is the key to dispersion: understanding eruption dynamics by inverting tephra fallout. In: Mader HM, Coles SG, Connor CB, Connor LJ (eds) Statistics in volcanology. IAVCEI Publications, Geological Society of London, pp 231242

Courtland LM, Kruse SE, Connor CB, Connor LJ, Savov IP, Martin KT (2012) GPR investigation of tephra fallout, Cerro Negro volcano, Nicaragua: a method for constraining parameters used in tephra sedimentation models. Bull Volcanol 74(6):1409-1424. doi:10. 1007/s00445-012-0603-3

Fero J, Carey SN, Merrill JT (2009) Simulating the dispersal of tephra from the 1991 Pinatubo eruption: implications for the formation of widespread ash layers. J Volcanol Geotherm Res 186(1-2):120 131. doi:10.1016/j.jvolgeores.2009.03.011

Fierstein J, Nathenson M (1992) Another look at the calculation of fallout tephra volumes. Bull Volcanol 54(2):156-167. doi:10.1007/ BF00278005

Hayami A (1993) Population Statistics Corpus before the National Population Census. Toyo Shorin, Tokyo, pp 2-9 (Japanese)

Heffter JL (1965) The variation of horizontal diffusion parameters with time for travel periods of one hour or longer. J Appl Meteorol 4(1): $153-156$ 
Inoue K (2011) Distribution of sediment-related disasters after the Hoei eruption of Fuji volcano in 1707, based on historical documents. In: Aramaki S, Fujii T, Nakada S, Miyaji N (eds) Fuji Volcano. Volcanological Society of Japan, pp 427-439 (Japanese with English abstract)

Ishii Y, Aramaki S, Miyaji N, Kobayashi M (2007) C4: Workshop and field excursion: Fuji volcano. Cities on Volcanoes 5 conference. Shimabara, Japan. November 19-23, 2007

Kalnay E, Kanamitsu M, Kistler R, Collins W, Deaven D, Gandin L, Iredell M, Saha S, White G, Woollen J, Zhu Y, Leetmaa A, Reynolds B, Chelliah M, Ebisuzaki W, Higgins W, Janowiak J, Mo KC, Ropelewski C, Wang J, Jenne R, Joseph D (1996) The NCEP/NCAR 40-Year Reanalysis Project. Bull Am Meteorol Soc 77(3):437-472

Koyama M (2011) Database of eruptions and other activities of Fuji volcano, Japan, based on historical records since AD 781. In: Aramaki S, Fujii T, Nakada S, Miyaji N (eds) Fuji Volcano. Volcanological Society of Japan, pp 119-136 (Japanese with English abstract)

Koyama M, Maejima Y (2009) Estimate of the height of eruption column of the 1707 Hoei eruption of Fuji Volcano, Japan, based on historical documents and CG scenery reconstruction. Programme and abstracts the Volcanological Society of Japan 2009: A8 (Japanese)

Machida H, Arai F (1988) A review of late Quaternary deep-sea tephras around Japan. Quat Res Jpn 26(3):227-242 (Japanese with English abstract)

Mannen K (2014) Particle segregation of an eruption plume as revealed by a comprehensive analysis of tephra dispersal: theory and application. J Volcanol Geotherm Res 284:61-78. doi:10.1016/j. jvolgeores.2014.07.009

Miyaji N (1984) Wind effect on the dispersion of the Fuji 1707 tephra. Bull Volcanol Soc Jpn Series 2 29(1):17-30 (Japanese with English abstract)

Miyaji N (2002) The 1707 eruption of Fuji Volcano and its tephra. Global Environ Res 6(2):37-39

Miyaji N (2011) Eruptive history, eruption rate and scale of eruptions for the Fuji Volcano during the last 11,000 years. In: Aramaki S, Fujii T, Nakada S, Miyaji N (eds) Fuji Volcano. Volcanological Society of Japan, pp 79-95 (Japanese with English abstract)

Miyaji N, Koyama M (2002) Sequence of magma discharge rates of the 1707 Hoei eruption of Fuji Volcano, Japan. Abstr Jpn Earth Planet Sci Joint Meet 32:24

Miyaji N, Koyama M (2011) Recent studies on the 1707 (Hoei) eruption of Fuji volcano. In: Aramaki S, Fujii T, Nakada S, Miyaji N (eds) Fuji Volcano. Volcanological Society of Japan, pp 339-348 (Japanese with English abstract)

Miyaji N, Kan'no A, Kanamaru T, Mannen K (2011) High-definition reconstruction of the Hoei eruption (AD 1707) of Fuji volcano,
Japan. J Volcanol Geotherm Res 207(3-4):113-129. doi:10.1016/j. jvolgeores.2011.06.013

Nelder JA, Mead R (1965) A simplex method for function minimization. Comput J 7(4):308-313. doi:10.1093/comjnl/7.4.308

Pasquill F (1974) Atmospheric diffusion, 2nd edn. John Wiley \& Sons, Chichester

Press WH, Teukolsky SA, Vetterling WT, Flannery BP (2007) Numerical recipes: the art of scientific computing, third edition. Cambridge University Press

Pyle DM (1989) The thickness, volume and grainsize of tephra fall deposits. Bull Volcanol 51(1):1-15. doi:10.1007/BF01086757

Pyle DM (1995) Assessment of the minimum volume of tephra fall deposits. J Volcanol Geotherm Res 69(3-4):379-382. doi:10.1016/ 0377-0273(95)00038-0

Scollo S, Tarantola S, Bonadonna C, Coltelli M, Saltelli A (2008) Sensitivity analysis and uncertainty estimation for tephra dispersal models. J Geophys Res 113:B06202. doi:10.1029/2006JB004864

Shimozuru D (1983) Volcano hazard assessment of Mount Fuji. Nat Disaster Sci (Kyoto Univ) 5:15-31

Siegel S (1956) Non-parametric statistics for the behavioral sciences. McGraw-Hill, New York, pp 75-83

Sumiya H, Inoue K, Koyama M, Tomita Y (2002) Distribution of sediment disasters after the 1707 Hoei eruption of Fuji Volcano in central Japan, based on historical documents. Hist Earthquake Stud 18:133147 (Japanese with English abstract)

Suzuki T (1983) A theoretical model for the dispersion of tephra. In: Shimozuru D, Yokoyama I (eds) Arc volcanism, physics and tectonics. Terra Scientific Publishing, Tokyo, pp 95-113

Takada A, Ishizuka Y, Nakano S, Yamamoto T, Kobayashi M, Suzuki Y (2011) Characteristic and evolution inferred from eruptive fissures of Fuji volcano, Japan. In: Aramaki S, Fujii T, Nakada S, Miyaji N (eds) Fuji Volcano. Volcanological Society of Japan, pp 183-202 (Japanese with English abstract)

Tsuya H (1955) Geological and petrological studies of Volcano Fuji (V5), on the 1707 eruption of Volcano Fuji. Bull Earthq Res Inst Univ Tokyo 33:341-383

Volentik ACM, Bonadonna C, Connor CB, Connor LJ, Rosi M (2010) Modeling tephra dispersal in absence of wind: insights from the climactic phase of the 2450 BP Plinian eruption of Pululagua volcano (Ecuador). J Volcanol Geotherm Res 193(1-2):117-136. doi: 10.1016/j.jvolgeores.2010.03.011

Watanabe S, Widom E, Ui T, Miyaji N, Roberts AM (2006) The evolution of a chemically zoned magma chamber: the 1707 eruption of Fuji volcano, Japan. J Volcanol Geotherm Res 152(1-2):1-19. doi: 10.1016/j.jvolgeores.2005.08.002

Wilcoxon F (1945) Individual comparisons by ranking methods. Biom Bull 1(6):80-83. doi:10.2307/3001968

Woods AW (1988) The fluid dynamics and thermodynamics of eruption columns. Bull Volcanol 50(3):169-193. doi:10.1007/BF01079681 